\title{
Communication about the Heart Failure Trajectory in Patients, their Families and Health Care Professionals
}

\author{
Lisa Hjelmfors
}

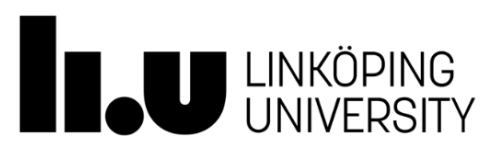

\author{
Division of Nursing Science \\ Department of Social and Welfare Studies \\ Linköping University, Sweden \\ Linköping 2018
}


@Lisa Hjelmfors, 2018

Cover picture: JoAnna S Fransson

Article I has been reprinted with the permission of the copyright holder.

Article II has been reprinted with the permission of JOURNAL OF PALLIATIVE MEDICINE, Volume 18. Issue 10, by Hjelmfors et al., published by Mary Ann Liebert, Inc., New Rochelle, NY.

Article IV is reprinted in the format of the final peer-reviewed version with permission of the copyright holder.

Printed in Sweden by LiU-Tryck, Linköping, Sweden, 2018

ISBN 978-91-7685-356-6

ISSN $0345-0082$ 
To Simon

"Communication is an important component in health care. Perhaps the most important. If St Paul had been a physician and missionary in Sweden today, he would have preached: -If I can diagnose Lyme disease and IBS but lack communication skills, I am no more than an echo or a rattling cymbal. If I have surgical talent and have cut my way into all the nooks and crannies of the body but lack communication skills, I am nothing. If I have 185 published articles and know every function of SPSS but lack communication skills, I have gained nothing. But science, evidence and communication are now prevailing. And of these, communication is the greatest."

Henrik Widegren, phoniatrician at Skåne University Hospital 



\section{CONTENTS}

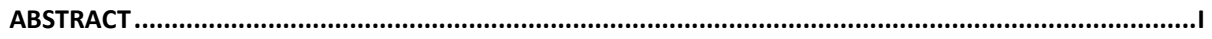

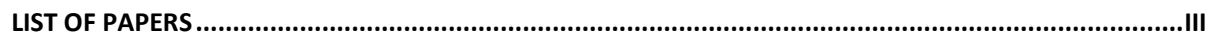

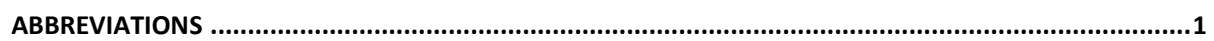

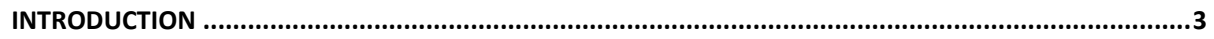

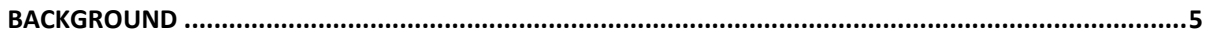

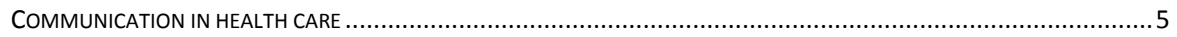

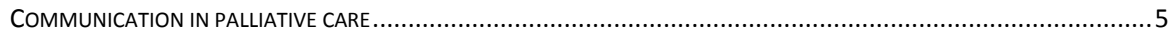

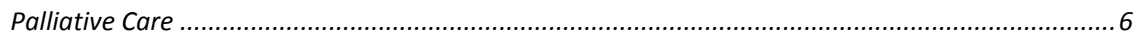

Specific issues for communication in palliative care ................................................................ 6

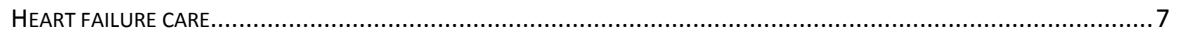

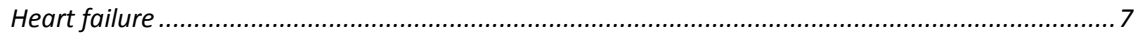

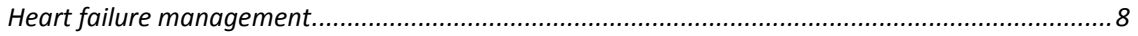

Specific issues in communication in heart failure care .............................................................

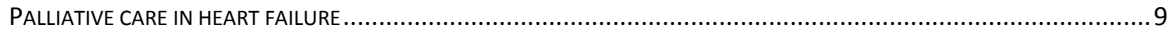

Palliative care communication in heart failure care ................................................................. 11

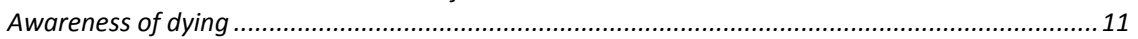

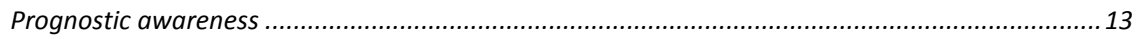

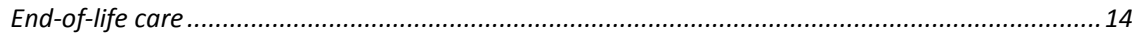

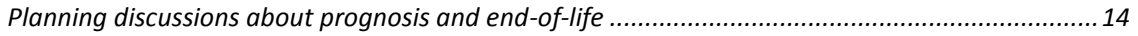

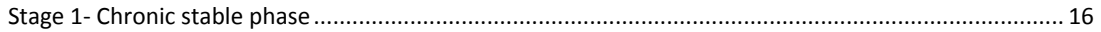

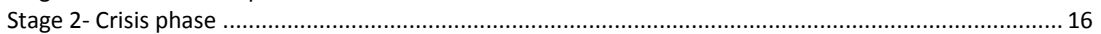

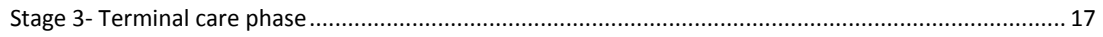

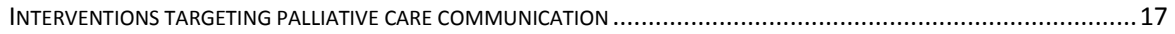

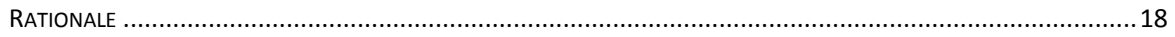

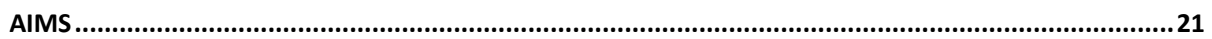

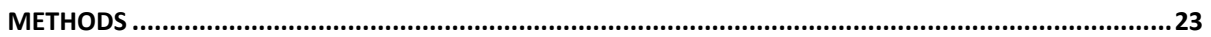

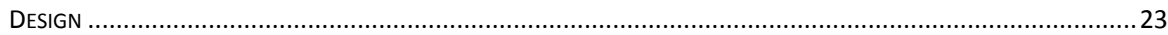

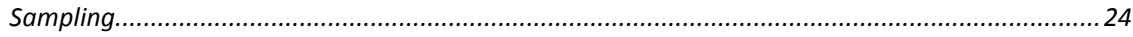

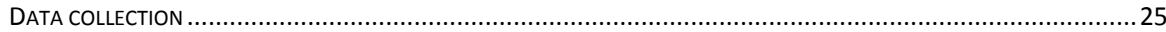

Questionnaire on perceptions about discussing prognosis and end-of-life care .............................25

Registration form on prevalence and practice of discussing prognosis and end-of-life care .............26

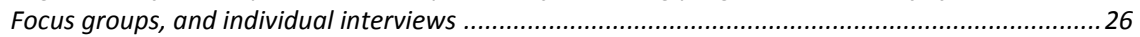

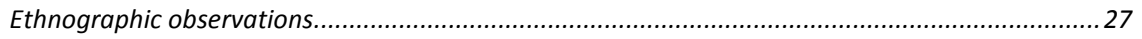

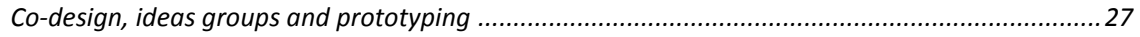

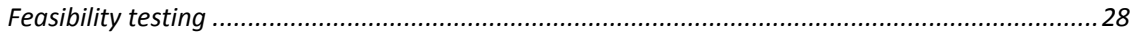

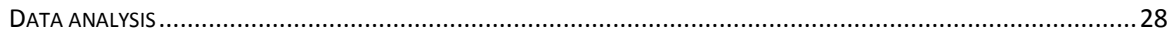

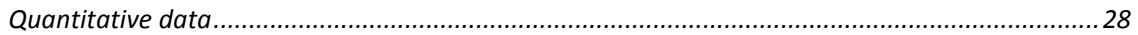

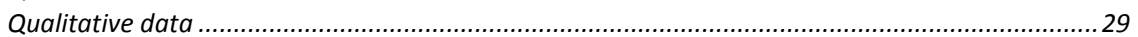

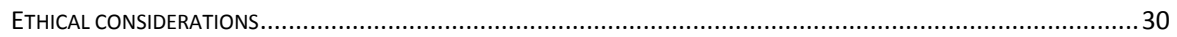

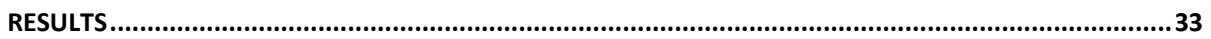

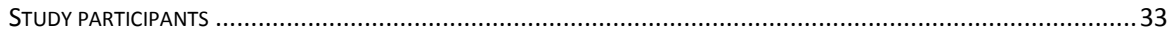

HF NURSES' PERSPECTIVE ON COMMUNICATION ABOUT PROGNOSIS AND END-OF-LIFE CARE .................................. 35

PRACTICE OF DISCUSSING PROGNOSIS AND END-OF-LIFE CARE IN A PATIENT EDUCATION CONTEXT................................36

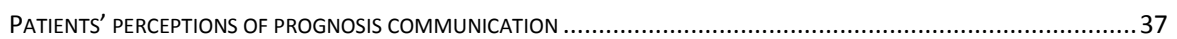

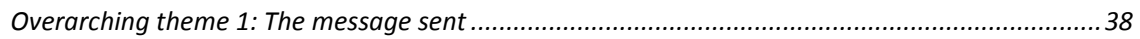

Overarching theme 2: Hoping for the best or preparing for the worst ..........................................38 


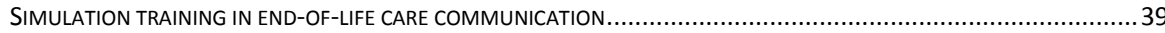

INTERVENTION TO IMPROVE COMMUNICATION...................................................................................... 41

The Question Prompt List for patients and their family members........................................................ 41

The communication course for health care professionals .................................................................. 42

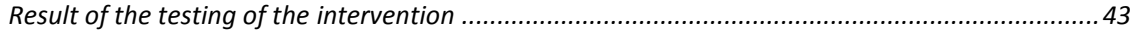

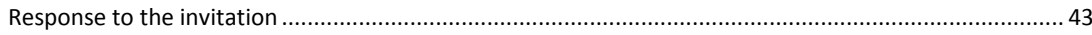

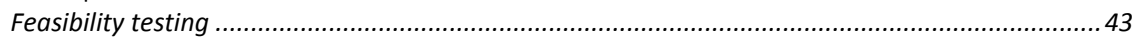

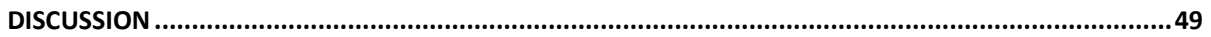

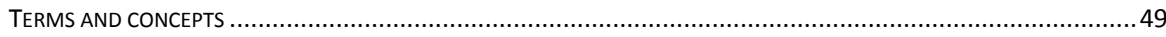

Prognosis and end-of-life care versus HF trajectory............................................................ 49

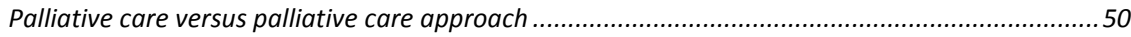

HEART FAILURE NURSES' PERCEPTIONS OF COMMUNICATION ABOUT THE HF TRAJECTORY ......................................50

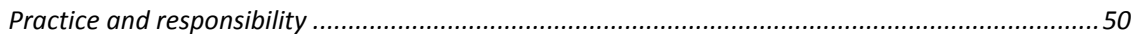

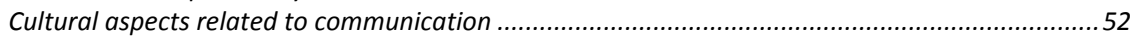

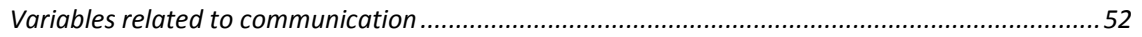

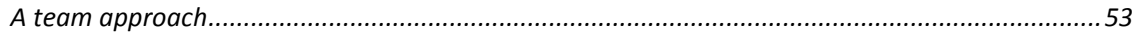

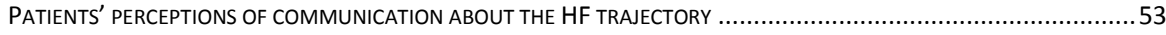

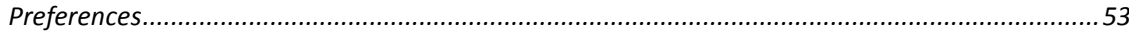

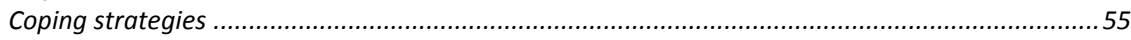

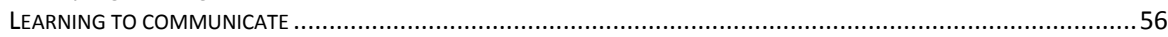

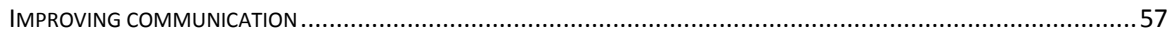

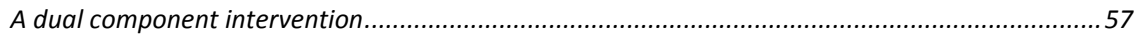

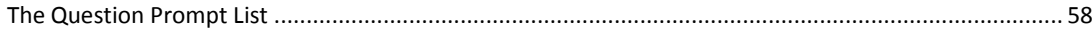

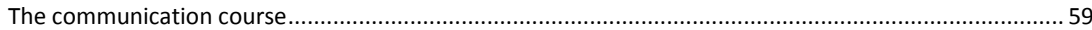

Patient-professional communication in health care ..................................................................5

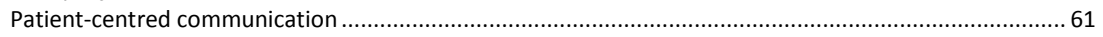

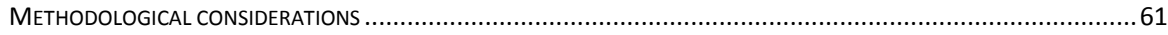

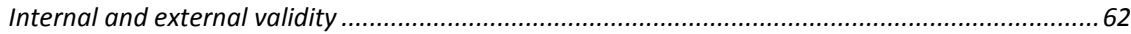

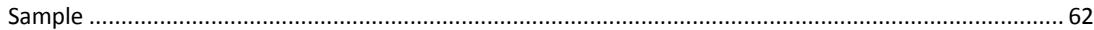

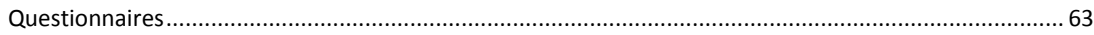

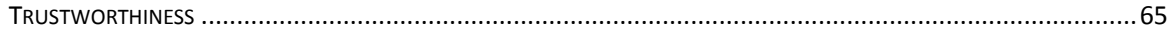

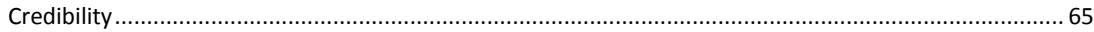

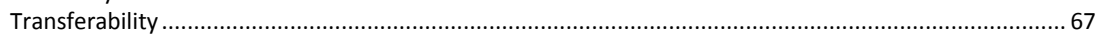

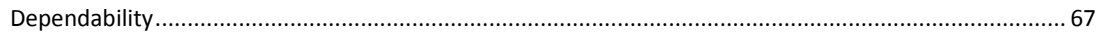

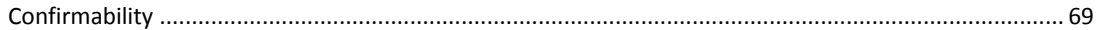

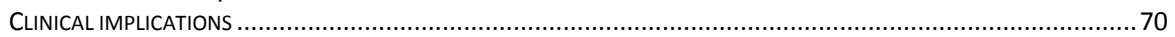

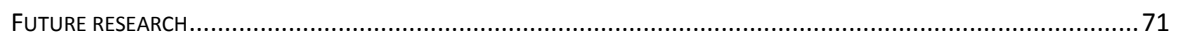

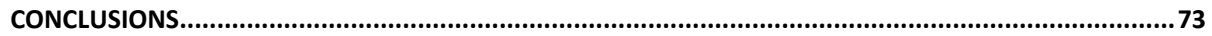

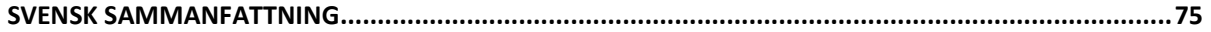

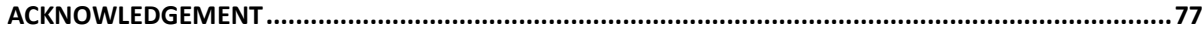

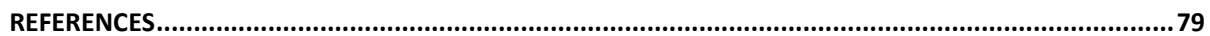




\section{ABSTRACT}

Introduction: There is an increasing awareness in the field of cardiology regarding the need of improved delivering of palliative care in patients with Heart Failure. Professional guidelines call attention to the importance of discussing the Heart Failure trajectory with patients and their families. These discussions can include for example talking about the prognosis, expectations for the future, and care in the end-of-life. For professionals it seems difficult to choose the right time for initiating these discussions, and professionals often avoid these conversations because they are afraid of taking away hope and cause anxiety in patients and their families.

Aim: The overall aim with this thesis was to improve communication about the heart failure trajectory in patients, their families, and health care professionals.

Design and methods: This thesis includes five studies using different designs and data collection methods. Study I had a cross-sectional design using a questionnaire to collect data to describe Heart Failure nurses' perceptions of and practice in discussing about prognosis and end-of-life care with Heart Failure patients. Study II was a descriptive and comparative study where a survey describing Swedish and Dutch Heart Failure nurses' reasons for discussing or not discussing prognosis and end-of-life care with patients. Study III has an inductive and exploratory design where HF patients participated in focus group-, or individual interviews and data was collected on their perceptions of communication about the Heart Failure prognosis. Study IV was a small-scale ethnographic study to describe and evaluate the delivery of simulation when teaching third-year nursing students about end-of-life care at a Swedish University. Study V used co-design in which patients with HF from primary care, their family members and health care professionals (physicians and nurses) from palliative and HF care, were invited to be constructive participants in the design process of a communication intervention, and health care professionals participated in a first feasibility testing of the intervention.

Results: Most Swedish HF nurses had discussed prognosis (96\%) and end-of-life care (84\%) with a HF patient at some point in clinical practice. The nurses often reported that a physician was be the main responsible for such discussions (69\%) but the nurse was also believed to have a role to play (I). Prognosis and end-of-life care were (together with sexual activity) 
the three least frequently discussed topics in HF clinics in both Sweden and the Netherlands (II). In conversations with 1809 Swedish and Dutch HF patients, prognosis was discussed with $38 \%$ and end-of-life care was discussed in $10 \%$ of the patients. In study III, patients expressed different experiences and preferences of communication about the HF prognosis. Many patients described that professionals had not provided them with any prognosis information at all. The patients had different understandings of $\mathrm{HF}$ as a chronic illness which had an impact on their preferences of communication about the prognosis (III). The simulation training described in the ethnographic study (IV) was part of an end-of-life care simulation used during the last term of the 3-year bachelor's degree level nursing education when the students learn and practice basic palliative care. The students felt that the simulation training was a good opportunity to practice handling end-of- life situations as it gave them a chance to experience this situation and their own feelings and thoughts on death and dying. In study V, an intervention to improve communication about prognosis and end-of-life care in HF care was developed and some areas of feasibility were tested. The intervention consisted of a Question Prompt List for patients and family members and a communication course for health care professionals.

Conclusions: This thesis shows that prognosis and end-of-life care were seldom discussed with HF patients in Swedish and Dutch Heart Failure care and that many Heart Failure nurses have ambiguous attitudes concerning discussing these topics with patients and their families (I+II). Patients have described that they receive different kinds of messages concerning their heart failure, and patients also have different preferences for discussing the Heart Failure trajectory with professionals. Patients want the professionals to understand what impact Heart Failure has on each patient and adopt the communication individually (III). End-of-life care simulation with skilled supervisors, can be a promising way for nursing students and health care professionals to learn good communication skills in endof-life care conversations (IV). A Question Prompt List and a communication course might be useful in improving communication about the Heart Failure trajectory in patients, their families, and health care professionals.

Keywords: Heart failure, nurse attitudes, prognosis, end-of-life care, communication, palliative care, end of life care education, simulation, undergraduate nursing students, co-design 


\section{LIST OF PAPERS}

This thesis is based on the following papers, which will be referred to in the text by their Roman numerals.

I. Hjelmfors L, Strömberg A, Friedrichsen M, Mårtensson J, Jaarsma $\mathrm{T}$. Communicating prognosis and end-of-life care to heart failure patients: A survey of heart failure nurse's perspectives. European Journal of Cardiovascular Nursing 2014, 13(2) 152-161. doi: 10.1177/1474515114521746.

II. Hjelmfors L, van der Wal MHL, Friedrichsen M, Mårtensson J, Strömberg A, Jaarsma T. Patient-Nurse communication about prognosis and end-of-life care. Journal of Palliative Medicine. 2015, 18. Doi :10.1089/jpm.2015.0037.

III. Hjelmfors L, Sandgren A, Strömberg A, Mårtensson J, Jaarsma T, Friedrichsen M. 'I was told I would not die from heart failure: Patient perception of prognosis communication. Accepted.

IV. Hjelmfors L, Strömberg A, Karlsson K, Olsson L, Jaarsma T. Simulation to teach nursing students about end-of-life care. Journal of Hospice and Palliative Nursing 2016, 18 (6) p. 512-18. Doi : 10.1097/NJH.0000000000000279.

V. Hjelmfors L, Strömberg A, Friedrichsen M, Sandgren A, Mårtensson J, Jaarsma T. Using co-design to develop an intervention to improve communication about the heart failure trajectory and end-oflife care. Re-submitted. 


\section{ABBREVIATIONS}

BNP

CRT

ESC

$\mathrm{HF}$

ICD

IQT

MI

NT pro-BNP

NYHA-class

PBL

PM

QPL

RCT

SPSS

WHO
Brain Natriuretic Peptide

Cardiac Resynchronization Therapy

European Society of Cardiology

Heart Failure

Implantable Cardioverter Defibrillator

Interquartile Range

Myocardial Infarction

N-Terminal pro-Brain Natriuretic Peptide

New York Heart Association functional classification

Problem-Based Learning

Pacemaker

Question Prompt List

Randomised Controlled Trial

Statistical Package for Social Science

World Health Organization 


\section{INTRODUCTION}

Before I start my scientific thesis, I would like to share a case description that might help the readers of this thesis to appreciate the relevance of the scientific work in the perspective of everyday lives of patients with chronic heart failure.

Inga Eriksson, 75 years old, is a retired teacher who lives in a small townhouse on the outskirts of a small village in Sweden. She has been living alone since her husband died a few years ago. She has a good relationship with her daughter Stina, who engages a lot in her mother's life.

In May 2016, Inga was diagnosed with atrial fibrillation and heart failure by a cardiologist. In September 2016, she received a pacemaker with a defibrillator (CRT-D) to help the heart pump more efficiently. Inga says she feels better than for a very long time and looks forward to the future. She says that she "runs on a battery", so Inga thinks her heart will never stop beating.

When Inga visits the HF clinic she has many thoughts about the future and how her heart now functions with the implanted device. Her daughter Stina, who accompanies her to the clinic, is worried about her mother and would like to discuss various things with a health care professional, but she does not know how to initiate such a conversation and with whom.

They meet the HF nurse Lotta at the HF clinic. She checks Inga's blood pressure, her pulse and monitors her weight. She asks Inga if she has gained any weight the last couple of weeks. She also asks if Inga has felt any breathless or fatigued, if her ankles have been swollen and if she has been able to go for walks recently or if she has been too tired.

Both Inga and Stina appreciate the nurses' caring attitude and think that she seems to know all there is to know about HF symptoms and treatments. However, they would like to talk about the future and what can be done if Inga's HF symptoms become worse. They want to discuss whether the device can prevent her heart from stopping beating, and whether it means that she can never actually die.

Both Inga and Stina are waiting for the nurse to say something that could lead the conversation towards these issues, but that moment somehow does not present itself and they leave the clinic feeling somewhat frustrated. 
"Next time, we have to ask our questions", Stina says to her mother, "but it is difficult to find the right moment. The nurse should have asked us if we had any concerns". "Well, maybe she is waiting for us to take the first step" replies Inga. 


\section{BACKGROUND}

This thesis gives health care professionals, patients and their families a voice and involves them in becoming important contributors in finding answers about how communication about the heart failure (HF) trajectory can be improved. This first section describes why communication about the $\mathrm{HF}$ trajectory is important and how efficient communication can improve palliative care for HF patients and their families.

\section{Communication in health care}

Communication derives from the Latin word "communis", which means "in common" and emphasizes a "sharing" of information (1). Fiske (2010) defines communication as a social interaction through some kind of messages. It is a diverse and multi-faced process in which individuals share and receive information through symbolic behaviour, for example by using language. In communication, each individual brings unique characteristics, values, beliefs and experiences into the interaction. These factors might influence the communication (2). According to Fiske (3), there are two main schools when studying communication. The first school defines communication as a process, a transmission of messages where one sender affects the behaviour and mind of a receiver. The other school regards communication as an exchange of meanings and concerns itself with how texts or messages produce meaning to people. Fiske labels this school the semiotic school.

In health care, communication is a core clinical skill. Both what and how the professionals communicate to patients and family members are important. There is a correlation between good patient-professional communication and health outcomes for the patient (4), where effective communication can improve patient and family satisfaction, understanding of the illness, adherence and outcome of care (5). Both the professional and the patient need knowledge, skills and motivation to be able to have a good communication. The health care environment also has to facilitate the communication process (6).

\section{Communication in palliative care}

Palliative care is one area in health care where patient-professional communication is of great importance (7). 


\section{Palliative Care}

The World Health Organization (WHO) defines palliative care as "an approach that improves the quality of life of patients and their families facing the problem associated with life-threatening illness, through the prevention and relief of suffering by means of early identification and impeccable assessment and treatment of pain and other problems, physical, psychosocial and spiritual" (8).

Palliative care is characterized by a holistic view of a person by supporting the individual to live with dignity and with the best possible well-being until the end of life, regardless of age and diagnosis. Palliative care aims to prevent and alleviate suffering through early detection, careful analysis and treatment of physical, mental, social and existential problems through collaboration in multi-professional teams. Palliative care can also be given early in the disease trajectory along with life prolonging treatment (9).

Basic palliative care can be provided by professionals in both primary care and by specialized professionals providing care for people with serious illnesses. Specialized palliative care is provided by specialists in palliative medicine, social work, nursing and other palliative care fields (10).

The Swedish government agency The National Board of Health and Welfare (9) describes the four corner stones of palliative care as follows:

- Symptom control to relieve pain and other difficult symptoms, taking into account the patient's integrity and autonomy. Symptom control includes physical, mental, social and existential/spiritual needs

- Collaboration in a multi-professional team. The team includes physicians, nurses and others

- Communication to promote the patient's quality of life. A good mutual communication and relationship within and between teams and to the patient and their family members

- Support for family members during the disease and after death. The family members should be offered to participate in the care and receive support themselves.

\section{Specific issues for communication in palliative care}

Effective delivery of palliative care is not possible without optimal communication. Good communication skills are believed to be an important clinical component in the interaction between health care professionals and patients, which could improve quality of life for both parties (7). 
Communication in palliative care includes:

- Basic listening skills: deals with the physical context of communication, and the health care professional's empathic responses and facilitating communication techniques

- The specific communication tasks in palliative care: (a) breaking bad news - where medical information is delivered to the patient, and (b) therapeutic dialogue - which centres around the patient's emotions and feelings

- Communication with the family and other professionals: acknowledging the family's situation and the importance of effective communication between professionals (11).

Communication can also involve non-verbal communication, such as just being present in the moment, sharing emotions, sitting next to the patient with or without touching, daring to be silent (12).

The quality of communication between professionals and patients in palliative care is sometimes poor, especially with respect to discussing prognosis, dealing with spiritual concerns and emotions, and finding a good balance between hoping for the best and preparing for the worst. Professionals in all disciplines and specialties providing care to patients with serious illness should be competent in basic palliative care, including communication (10).

\section{Heart failure care}

\section{Heart failure}

Overall, 1-2\% of the adult population in the western world have HF. In people 75 years of age the prevalence increases to $\geq 7 \%$ and in those aged $\geq 85$ year it increases to $\geq 10 \%(13,14)$.

Many patients with HF have a poor prognosis and are often highly symptomatic during the time they live with HF, particularly in the end-of-life (15-17). Heart failure has a major influence on patient's emotional, physical, spiritual and social dimensions. This day-to-day uncertainty of living with HF influences the well-being of the patient and the family (18). Heart failure has been described as more malignant than many of the most common types of cancer, such as prostate-, breast-, bladder-, and colorectal cancer (19). Death from HF can be sudden due to an ischemic event or electric instability. It can also be slow due to episodes of decompensation or 
progressive organ failure (20). The HF trajectory often has several exacerbations, plateaus of variable lengths with a high functional status and a risk of sudden death at any time during the course of the illness (21). Heart failure is an illness that reduces longevity in patients and causes symptoms of breathlessness, fatigue, ankle swelling, dyspnoea and reduced exercise tolerance due to an abnormality of cardiac structure or function (22).

New York Heart Association functional classification (22) is used to classify $\mathrm{HF}$, based on symptom severity and physical activity:

- Class I: No limitation of physical activity

- Class II: Slight limitation of physical activity

- Class III: Marked limitation of physical activity

- Class IV: Unable to carry on any physical activity without discomfort.

\section{Heart failure management}

For most patients, heart failure is a lifelong illness requiring adequate selfcare, appropriate medical treatment (pharmacological and non-pharmacological), and regular follow-up by health care services (22).

After a patient is diagnosed with HF, most of the time he/she receives follow-up care within a HF management program. HF treatment aims to compensate for decreased cardiac output by reducing symptoms, improving survival and preventing hospital admission (22). Patients with a high risk of sudden cardiac death and malignant arrhythmias are recommended for implantable cardioverter defibrillators (ICD) and/or cardiac resynchronisation therapy (CRT) to reduce mortality (23). Many patients with heart failure also have typical palliative care needs; multidimensional symptom suffering, communication and decision making needs, and family issues similar to those with incurable malignant disease $(15,17,21)$.

Optimal HF management includes: "an accurate diagnosis; the correct investigations and implementation of appropriate evidence-based therapy; education for both the patient and their carers; with the overall aim of improving both survival and quality of life."

Heart failure care is often provided by a multi-disciplinary team, most often including both nurses and physicians, but also dieticians, physiotherapists, social workers, pharmacists and psychologists (24).

Since 1990, HF management programs in Sweden have been led by HF nurses in HF clinics. The specific goals of HF care are: 
- To evaluate the patient's situation and needs, both physical and mental, to titrate medications according to the prescription of the cardiologist

- To evaluate symptoms, status and sign of deteriorations

- To support the patient and family in performing appropriate selfcare

- To provide telephone support

- To provide psychosocial support to the patient and family (25).

Research has shown that nurse-led HF clinics can improve self-care behaviour and survival in patients, and reduce events, readmissions and days in hospital $(26,27)$.

\section{Specific issues in communication in heart failure care}

In communications in HF care, professionals need to involve the patient in proper self-care in order to manage their illness and maintain good health. The patient needs, for example, information that he/she should try to adapt their level of physical activity according to their heart's capacity and understand signs of deteriorations and when to seek care $(28,29)$.

However, many patients with HF have comorbidities that can cause cognitive impairment, and HF can itself lead to cognitive impairment $(22,30)$. These cognitive impairments often have a negative influence on the patient's memory, attention and language, making it more difficult for them to adhere to self-care regimens and recognize symptoms of exacerbations (31).

\section{Palliative care in heart failure}

Position statements from the United States, Canada and Europe, emphasize the importance of providing palliative care for patients with $\mathrm{HF}$ and their families $(15,32,33)$.

In recent guidelines, the European Society of Cardiology (ESC) stated (22) that the key components of palliative care for HF patients include:

- Focus on improving or maintaining the quality of life

- Frequent assessment of symptoms

- Access for the patient and his/her family to psychological support 
- Advanced care planning, taking account of preferences for place of death and resuscitation.

A recent review (34) that summarized the current evidence for palliative care interventions in HF patients found that palliative care interventions that are combined with HF management can improve patient outcomes and decrease costs and utilization (34). Another recent randomized controlled trial, the PAL-HF study, (Palliative Care in Heart Failure trial) investigated patient-reported outcomes and found that the addition of palliative care to evidence-based HF care improves quality of life, psychosocial (anxiety/depression) and physical aspects, and spiritual well-being compared to just usual care (35).

However, only a limited number of patients receive palliative care that prepares them for an optimal life with their illness, helping them to plan for the future together with their families, and discuss the impact HF could have on their lives $(15,21,33)$.

A Swedish registry study evaluated 31 o6o deaths from heart disease and concluded that only $10.6 \%$ of the patients with heart diseases die in a palliative care setting. Furthermore, few patients and their families are aware of the possible symptoms that could occur during the illness trajectory and the imminence of death (36).

In a study from the United Kingdom, the worlds' largest primary care database was explored to find how many HF patients were recognized as needing a palliative care approach. Of the HF patients that were in the database, $7 \%(234 / 3122)$ were in a palliative care register compared to $48 \%$ (3669/7608) of cancer patients. Twenty-nine HF patients were entered into the register just within a week of their death. This is suggested to further confirm a inequality between HF and cancer care. The authors suggest a change in practice, where palliative care is offered depending on the patient's needs throughout the illness trajectory. This would replace providing palliative care based on prognosis criteria in the last phase of life, as the prognostication of HF is very difficult (37). The trajectory of HF is often unpredictable, which is why it is difficult to identify a specific when palliative care should be considered (38).

However, the implementation of palliative care in HF care does not have to be based on prognostication or risk of death, but instead on recognition of the palliative care needs of the patient (39). Palliative care can be offered in parallel with usual HF care throughout the whole illness trajectory (40). HF patients should not need to confront all the issues that can be connected 
with a life-limiting illness without the support of the health care services, including the fullest range of palliative care services (41).

\section{Palliative care communication in heart failure care}

As discussed in the section about communication in palliative care and heart failure care effective delivery of palliative care for heart failure patients care is not possible without optimal communication (42).

Many HF patients are not aware of their poor prognosis or the severity of HF $(43,44)$. Patients have expressed that some of the information they receive from the health care professionals is not adequate. They want to be better informed about their prognosis and want to feel that the professionals listen to them (45). Honest and competent delivery of information maximizes the patients' comprehension of their prognosis (46). Equally important, the delivered information should be relevant to the HF patients' actual situation (47). Some patients welcome frank discussions about prognosis (31) although this may change as end-of-life seems closer (48). At this point, some patients want less information and their families want more (49).

From the patients' point of view, optimal communication satisfies the needs for information, and it is also built on relationships of trust (48). According to patients, it is fundamental for a good end-of-life care that health care services coordinate a comprehensive and effective communication with them, which also includes family members (50-52) .

In heart failure care, there are some specific issues to consider that are related to communication, such as lack of awareness of dying and prognostic awareness.

\section{Awareness of dying}

In 2011, Barclay and Momen suggested that the situation in current HF care is similar to the time in cancer care when prognosis and end-of-life was not openly discussed with cancer patients (53). They referred to the cancer care context described by Glaser and Strauss in the 1960s. They observed and interviewed dying cancer patients at six hospitals in San Francisco. The results of their intensive field-work are presented in the classic book "Awareness of dying", where Glaser and Strauss describe four types of awareness contexts and what the dying patients at the hospitals knew about their life-limiting illness: 
- Closed awareness - the patient does not understand his/her impending death because the professionals keep this information from the patient

- Suspicion awareness - the patient suspects he/she is dying and tries to have this confirmed by the professionals

- Mutual pretence - both the patient and the professional know the patient is dying, but pretend that the patient is going to live

- Open awareness - both the patient and the professional know that the patient is dying and are open about it (54).

In recent years, the concept "death preparedness" has been described. This concept incorporates the components awareness and acceptance. Death preparedness means "a transition of facilitated communication with a health care provider that leads to awareness and/or acceptance of end-oflife care" (55). In HF guidelines (15), an open and honest communication about the prognosis and discussions about preferences for future end-oflife care are suggested to be important. This approach can be translated to an open awareness context or the concept of death preparedness. Professionals in HF care should openly discuss the HF prognosis and options for end-of-life care with HF patients, thereby helping them to prepare for a life with a life-limiting illness, ending in a good death.

In 2005, the SHAPE study (Study of Heart failure Awareness and Perception in Europe) concluded that the general public's awareness of HF was low. There were misconceptions of the nature and severity of HF, as well as of the treatment and costs (56). Another study reported that many patients with a predicted survival of less than two years did not perceive HF as a terminal illness or understand the progression of the illness. Most patients blamed their symptoms on other comorbidities and old age and believed that nothing could be done about their symptoms (57). This illustrates the importance of information and education to patients in order to gain a better understanding of the HF diagnosis $(56,58)$.

Conversations about death and dying have both instrumental and existential dimensions. Often, the conversations focus on the instrumental dimension which refers to the process of communication, how it is initiated and conducted, including barriers and triggers. The existential dimension of the conversations refers to psychosocial aspects, particularly issues regarding mortality and how to avoid it (59). In addition, in the last weeks and days of life, bad news needs to be broken to the patient and the family members 
that the transition to the dying phase has begun. It is of vital importance that these conversations are held in order to enable a good death (60).

\section{Prognostic awareness}

In this thesis, prognosis is defined as "the expected trajectory of a disease in a specific individual".

Patients with HF seldom recall having had a conversation with a professional about their condition or prognosis (61), but indicate that good communication is fundamental for satisfying care (62). In diseases like AIDS and cancer, which have similar prognosis and severity as HF, prognosis is regularly discussed, and patients and families are encouraged to ask questions and set the agenda for the discussions (63). Discussing the prognosis helps for planning and preparing for living as good a life as possible, despite having a life-threatening illness. In the cancer care literature, Jackson et al. (2013) have described the concept "prognostic awareness" as "a patient's capacity to understand his or her prognosis and the likely illness trajectory". The authors further emphasised that the patient's prognostic awareness is an important factor of palliative care, as an understanding of the prognosis allows for medical decisions that are based on realistic goals, according to the patient's values and wishes (64).

Prognostic awareness is important from the perspective of the Swedish legislation. This regulates what health status information the patient should be given, and how, in order to improve shared decision-making and the patient's involvement in their care. In the Swedish "Patient Act" (2014:821), it is stated that the patient should be given information about his/her illness and what treatments are available, the expected trajectory of the illness and information about future care. The information should be adapted to the individual patient's preferences and needs and a desire from the patient to refuse information must be respected. The person who provides the information should as far as possible ensure that the patient has understood the content and meaning of the information provided $(65,66)$.

Swedish healthcare is known for its high quality. Compared to other countries, it is rated as one of the best in Europe (67). At the same time, the governmental report "Effective Care" (2016) described that care is lacking when it comes to involving patients by encouraging them to ask questions. Compared to other countries, patient involvement in care is low for people with chronic disease in Sweden, with less discussions with health care professionals about treatment goals and how patients themselves can take care of their illness. The report calls for action to include the patient as part of the health care team and states that it is important to support patients and 
their families to manage their own care as far as possible. Such an approach of care is in line with the new Swedish law, the "Patient Act"( 2014:821) (68), that emphasizes the importance of allowing patients be active partners in their own care process and in decision-making.

\section{End-of-life care}

In this thesis, end-of-life care is defined as "care during the time when the patient mainly receives palliative care and medical treatment, while at the same time rehabilitating treatment ceases or is minimised".

It has been shown that if prognosis is inadequately discussed, issues of endof-life care tend to be discussed too late in the illness trajectory, possibly producing an unsatisfactory end-of-life care for both patients and families (63). Instead, it has been suggested that discussions and planning for endof-life care should be included early on in the illness trajectory to meet the patient's goals, thereby facilitating decision-making regarding the treatment in future care (49).

Discussing end-of-life care also includes discussions about withholding cardiopulmonary resuscitation and deactivating ICDs for patients who have these devices $(52,69,70)$. It has been shown that many patients have several ICD shocks during the last days of their life, and that discussions about deactivation rarely take place $(43,44)$. Patients might regard the ICD as a solely beneficial device, having little insight about its possible impact on a peaceful death (45).

Some years ago, a systematic literature review investigated "end-of-life care conversations in heart failure" and found that conversations in HF care mostly focus on disease management and less on preferences and goals of care. The authors described that end-of-life care becomes "the elephant in the room", i.e., a topic which is rarely discussed as the patient waits for the professional to initiate a discussion about end-of-life care, while the professionals waits for a cue or a question from the patient to start such conversations (53).

\section{Planning discussions about prognosis and end-of-life}

Health care professionals need to balance discussions about prognosis and end-of-life care with the assurance that they will work with the patient and try to prolong life and improve quality of life (46). The risk of rapid deterioration or sudden cardiac death needs to be acknowledged early on in the illness trajectory. As patients develop advanced HF, discussions and plan- 
ning for end-of-life care become important (32). Professionals need to clarify patient's and family member's needs and tailor the information accordingly. It is also important to recognize that the patient's and the family members' information needs may vary at different time points in the illness trajectory $(47,48)$.

Although general communication rules are applicable to all chronically ill patients, there are also specific barriers relevant to HF care when it comes to discussing prognosis and end-of-life care. Some barriers are disease related, such as HF having an unpredictable trajectory $(15,50)$, the public perception that HF is benign in comparison with cancer (50), and the common therapeutic optimism within cardiology (71), where professionals might concentrate on the curative and technological aspects of care instead of focusing on the patient's and the family member's needs. Other barriers are related to health care professionals who find it difficult to choose the right time for initiating prognosis and end-of-life discussions with patients and their families. They tend to avoid these conversations because they are afraid of taking away hope and cause anxiety (53). It is a challenge for health care professionals to know if and when the patient and the family members are ready to communicate about these difficult topics (72).

Jaarsma \& Strömberg (2016) have developed an algorithm that can help and guide health care professionals in planning discussions about the HF trajectory and end-of-life care with patients and their family members. The algorithm includes three stages, each with a specific focus of on treatment and care. 


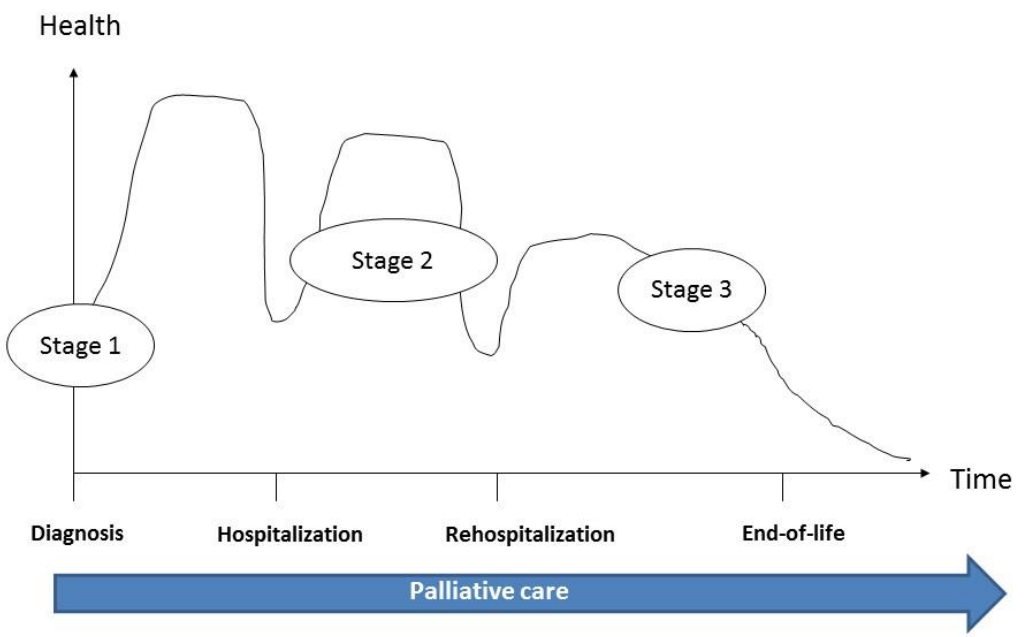

Figure 1. Focus and refocus of care in the HF trajectory.

\section{Stage 1- Chronic stable phase}

In this phase which occurs directly after diagnosis, the illness is often relatively stable and the patient needs routine chronic disease management. The focus and goal of care are:

- Patient education on prognosis

- Discussions about the patient s' preferences of care in case of deterioration

- Discussions about devices (CRT/ICD) in case of implantation.

\section{Stage 2- Crisis phase}

This phase includes hospitalization or re-hospitalization due to deteriorating HF. Patients and families might need psychosocial support, more education and monitoring of symptoms. Focus and goal of care are:

- Opportunities to discuss the likely course if the illness and the patients' preferences for advanced care planning

- A holistic assessment of the patient s' and families' needs 


\section{Stage 3- Terminal care phase}

In this last phase of life, patients are repeatedly hospitalized and have a poor prognosis, often with many disabling symptoms. Focus of treatment and care are:

- Planning and preparing for a good death

- Documentation of resuscitation preferences

- Review of devices and plans for possible deactivation in the end-oflife.

The authors emphasize the importance of focus and goals of care being evaluated and re-evaluated throughout the whole HF trajectory, as previous goals and preferences might become unrealistic (39).

\section{Interventions targeting palliative care communica- tion}

A recent systematic review found a substantial number of studies regarding prognostic/end-of-life communication in patients with life-limiting illness, most within a cancer care context. The review described that interventions developed to facilitate communications and interactions between patients and health care professionals in life-limiting illnesses have primarily been designed for professionals (73), and that different approaches to teaching professionals communication skills have been found to have an effect on professionals' communication behaviour (74).

Recently, there has also been a focus on increasing patients' communications skills and participation in discussions (73). However, it is not known what the most effective and appropriate communication strategies are in $\mathrm{HF}$ care to have a positive effect on both professionals and the patients/families. There is a clear need for further research to develop and evaluate interventions that are adapted to the specific features of communication with HF patients $(62,75)$. Furthermore, the interventions should be developed in accordance with the future users' needs and preferences to increase usefulness.

During the last few decades, methods where patients, family members and health care professionals are involved in the health care service design have become more common (76). These include experienced-based design, codesign and experienced-based co-design (77). Development studies often involve the future users' experiences and ideas in a co-design process of 
new services or products. Key benefits of co-design methods in development processes include the possibility to engage and empower patients, family members and health care professionals to become active participants in the development of services that they will use in the future $(77,78)$. The method is suggested to be a dynamic and relevant method in chronic illness research (79) and to fit particularly well in palliative care research, as the method focuses on the patients and their family's needs in the development process, regarding them as important shared decision-makers (77, 80). By using co-design researchers are working with the patient and the family to help them identify their needs and possible ways to meet those needs (79).

\section{Rationale}

Providing optimal HF care, communication is vital. In addition to communication about the treatment, and self-care, HF patients also need to discuss the trajectory of the illness and preferences for future care.

HF patients might need palliative care and some important issues when providing palliative care to HF patients in primary care include discussing the HF trajectory and establishing goals of end-of-life care.

Although it is generally recognized that HF is a serious illness, equivalent to cancer in terms of symptom burden and mortality, only a limited number of $t$ patients receive care that prepares them for planning and coping with the different stages of the illness. Throughout the HF trajectory, the treatment goals and care needs may change. Thus, decisions need to be taken, requiring good communication between patients, family members and health care professionals.

To improve the communication about the HF trajectory and in HF care, more knowledge is needed about the clinical practice concerning these conversations. Needs and possibilities for improvement also have to be identified. In other words, the need for change has to be established and possible barriers, needs or possibilities identified.

Many HF patients are cared for in nurse-led HF clinics. Previous studies have described the nurses' role, but they do not describe the nurses' own views of their role when it comes to discussing the HF trajectory. In addition, there is little knowledge if and why, or why not, HF nurses discuss the HF trajectory with patients. There is also a need to explore the patients' own perspectives of and preferences for communication about the HF trajectory. 
After possible needs have been identified, the development and testing of interventions can begin. To find an optimal way to improve communications about the HF trajectory communication intervention seem to be required. These interventions should be developed and tested together with the future users (patient/family member/health care professional), to make sure that the intervention meets their needs and preferences. 


\section{AIMS}

The overall aim with this thesis was to improve communication about the heart failure trajectory in patients, their families, and health care professionals.

The specific aims of the five studies were:

I. To describe HF nurses' perspectives on, and daily practice regarding discussing prognosis and end-of-life care with HF patients in outpatient care. It further aimed to explore barriers, facilitators and related factors for discussing these issues.

II. To expand on the knowledge of prevalence and practice of discussing prognosis and end-of-life care with HF patients in the context of patient education at nurse-led HF clinics, and compare this between two European countries with a long history of HF clinics, namely Sweden and the Netherlands.

III. To describe HF patients' experiences of prognosis communication and explore how these experiences affected their preferences for future communication about the prognosis.

IV. To increase the knowledge about end-of-life care simulation in nursing education by describing and evaluating the delivery of simulation when teaching third-year nursing students about end-of life care.

V. To describe the development of an intervention aimed to improve communication about the heart failure trajectory and end-of-life care, and to determine specific areas of feasibility of the intervention. 


\section{METHODS}

\section{Design}

This thesis includes five studies using different designs and data collection methods.

\begin{tabular}{|c|c|c|c|c|c|}
\hline & Study 1 & Study 2 & Study 3 & Study 4 & Study 5 \\
\hline Design & Cross sectional & $\begin{array}{l}\text { Descriptive and } \\
\text { comparative }\end{array}$ & $\begin{array}{l}\text { Inductive and } \\
\text { exploratory }\end{array}$ & $\begin{array}{l}\text { Small scale } \\
\text { ethnography }\end{array}$ & Co-design \\
\hline Setting & $\begin{array}{c}\text { Primary HF } \\
\text { care in Sweden }\end{array}$ & $\begin{array}{l}\text { Primary HF care } \\
\text { in Sweden and } \\
\text { the Netherlands }\end{array}$ & $\begin{array}{l}\text { Primary HF } \\
\text { care in Swe- } \\
\text { den }\end{array}$ & $\begin{array}{l}\text { Nursing educa- } \\
\text { tion in Sweden }\end{array}$ & $\begin{array}{l}\text { University in } \\
\text { Sweden }\end{array}$ \\
\hline $\begin{array}{l}\text { Partici- } \\
\text { pants }\end{array}$ & $111 \mathrm{HF}$ nurses & $\begin{array}{l}113 \text { Swedish } \\
\text { HF nurses and } \\
166 \text { Dutch HF } \\
\text { nurses docu- } \\
\text { mented } 1809 \\
\text { conversations } \\
\text { with Swedish } \\
\text { and Dutch HF } \\
\text { patients }\end{array}$ & $\begin{array}{l}24 \text { patients } \\
\text { with HF }\end{array}$ & $\begin{array}{l}\sim 60 \text { nursing } \\
\text { students }\end{array}$ & $\begin{array}{c}\text { Development: } \\
9 \text { patients, } 2 \\
\text { family mem- } \\
\text { bers, } 9 \text { health } \\
\text { care profes- } \\
\text { sionals (physi- } \\
\text { cian and } \\
\text { nurses) } \\
\text { Testing: } 16 \\
\text { health care } \\
\text { professionals } \\
\text { (physicians } \\
\text { and nurses) }\end{array}$ \\
\hline $\begin{array}{c}\text { Data } \\
\text { collection }\end{array}$ & Questionnaire & Questionnaire & $\begin{array}{l}\text { Focus group } \\
\text { and individual } \\
\text { interviews }\end{array}$ & $\begin{array}{l}\text { Observations, } \\
\text { field-notes, } \\
\text { video record- } \\
\text { ings, audio re- } \\
\text { cordings }\end{array}$ & $\begin{array}{l}\text { Question- } \\
\text { naires, ideas } \\
\text { groups and } \\
\text { prototyping, } \\
\text { field-notes, au- } \\
\text { dio recordings }\end{array}$ \\
\hline $\begin{array}{c}\text { Data } \\
\text { analyses }\end{array}$ & $\begin{array}{c}\text { Chi-square test, } \\
\text { Fischer's exact } \\
\text { test, Student's } \\
\text { t-test. Qualita- } \\
\text { tive content } \\
\text { analysis }\end{array}$ & $\begin{array}{l}\text { Chi-square test, } \\
\text { Student's t-test. } \\
\text { Qualitative con- } \\
\text { tent analysis }\end{array}$ & $\begin{array}{l}\text { Thematic } \\
\text { analysis }\end{array}$ & $\begin{array}{l}\text { Predetermined } \\
\text { question } \\
\text { guided areas } \\
\text { of interest for } \\
\text { evaluation }\end{array}$ & $\begin{array}{c}\text { Descriptive } \\
\text { analysis and } \\
\text { summaries of } \\
\text { qualitative data }\end{array}$ \\
\hline
\end{tabular}

Abbreviation: Heart Failure, HF. 
To describe HF nurses' perceptions of and practice in discussing prognosis and end-of-life care in HF care, questionnaires with both closed- and openended questions were used to collect data in study I-II. To describe HF patients' perspectives on communication about the HF prognosis, focus groups and individual interviews were performed (III). Study IV and V further explored and evaluated ways for communication training for health care professionals, by using ethnographic observations (IV) and co-design (V).

Study I had a cross-sectional design, where a survey was conducted among HF nurses with dedicated time for HF patients, who worked at Swedish hospitals or primary health care centres.

Study II used a descriptive and comparative design, where a survey was performed during specific study weeks in November 2012 and January 2013. It included nurses from Swedish and Dutch HF clinics. The nurses' reasons for discussing or not discussing prognosis and end-of-life care with the patients were collected by open-ended questions.

Study III used an inductive and exploratory design where HF patients in New York Heart Association class I-III from primary care participated in focus groups, or individual interviews.

Study IV used a small-scale ethnographic design to describe and evaluate the delivery of simulation when teaching third-year nursing students about end-of-life care at a Swedish university.

Study V used co-design. Patients with HF from primary care, their family members and health care professionals (physicians and nurses) from palliative and HF care were invited to be constructive participants in the design process of the intervention. The health care professionals participated in a first feasibility testing of the intervention.

\section{Sampling}

A researcher approached all HF clinics in Sweden by phone or email and invited HF nurses to participate in study I and II.

In study I, all Swedish hospitals and the primary health care centres who had HF nurses working with HF patients were eligible to participate. There were no further inclusion or exclusion criteria.

In study II, HF nurses at all hospitals in Sweden and the Netherlands and relevant Swedish public health care centres from study I were approached for participation. The participating nurses collected data on conversations 
with HF patients but the patients themselves did not participate in the study.

In study III and V, a purposeful sampling (78) was used, aiming to include participants with a range in sex, age, and severity of HF (III), and professional background (V). This was done to establish variation in the data, targeting participants who are most likely to provide an understanding of the phenomenon under research. In study III, two HF nurses in two cities in the south of Sweden, identified suitable patients and provided the names and contact information to the researchers.

Some of the patients (some with family members) from study III, also participated also in study $\mathbf{V}$.

The health care professionals in study $\mathbf{V}$ were recruited through the researchers' professional networks. They were invited by a personal email contact.

All nursing students who participated in the end-of-life care simulation were observed in study IV. None of the students disagreed to participate.

\section{Data collection}

\section{Questionnaire on perceptions about discussing prognosis and end-of-life care}

In study I, data was collected using a questionnaire that was inspired by a questionnaire on perceptions about sexual counselling (81). The researchers defined the concepts of prognosis and end-of-life care in the questionnaire to increase validity. Prognosis was defined as the expected trajectory of a disease in a specific individual. End-of-life care was defined as the time when the patient mainly receives palliative care and medical treatment, while at the same time rehabilitating treatment ceases or is minimized. The nurses were asked to answer questions about their perspectives (practice, attitude, responsibility, confidence and comfort of patient) on discussing prognosis and end-of-life care with HF patients.

Additional questions about possible barriers and facilitators for communication were also included. To analyse factors related to barriers, two groups were created based on the reported numbers of barriers, with $0-2$ barriers labelled as 'few' and the group with 3-7 barriers labelled as 'many'. The nurses could also add barriers and facilitators as well as other comments. 


\section{Registration form on prevalence and practice of discussing prognosis and end-of-life care}

In study II, data was collected using a short registration form where nurses were first asked to document the topics they discussed with the patient during the clinical visit (including prognosis and end-of-life care). They were also asked to report if they thought it was relevant to discuss prognosis and end-of-life care with the patient. In the next step, the nurses were asked to give reasons for discussing/not discussing prognosis and end-of-life care with the patient.

The registration form was developed by the research group. Face validity of the registration form was established by researchers experienced in $\mathrm{HF}$ care, palliative care and professional communication. Content validity was determined using six think-aloud interviews (82) with nurses with clinical HF experience. The registration form was translated into Dutch by a certified translation service and reviewed by a person fluent in Dutch and Swedish.

\section{Focus groups, and individual interviews}

To gain an insight into the patients' experiences and perspectives on communication about the HF prognosis, a research method with a descriptive and exploratory design was used including focus groups and individual interviews (III). In the focus group, data was produced from a group of patients discussing a topic that was of interest to the researchers $(83,84)$. The main aim of the method is to explain and understand the beliefs, meanings and culture that influence people's attitudes, feelings and behaviour (85). The method takes advantage of the dynamics in the group, making it possible to obtain information as the participants interact and respond to each other's experiences and perspectives, thereby producing rich information (86). Some participants might need to hear others talk about a topic and be inspired in order to talk themselves. In a focus group it is possible to have direct reactions and comparisons of differences and similarities in an economical way. The participants might also feel comfortable being in a group, hearing others' perspectives and learning from each other.

A moderator led the focus group interviews and took field-notes. An observer, who did not participate in discussions, took field-notes, summarized the discussion at the end of the interview and asked following-up questions when needed. Additional demographic data and the patients' medical background was individually collected before the focus group interviews started. This was also a way of establishing a good contact between the researcher and the patients (87). 
As a complement to the focus group interviews, additional individual interviews were performed. The aim was to include patients with more severe HF symptoms, but also to obtain richer data, as the data from the focus group interviews were considered somewhat sparse. In the individual interviews, only the researcher and the participant were present. The idea was that the interview situation would "feel safe" and more private for the participant so that he/she would feel confident to talk more freely.

A semi-structured interview guide with probing questions was used in both the focus group interviews and the individual interviews. Participants were asked to reflect on their experiences of and preferences for professional communication about the HF prognosis. The questions in the interview guide were based on literature from both palliative care (88) and heart failure care $(53,89)$. They were scrutinized by the research group and a patient who had been living with HF for a long time and had an interest in participating as a "research partner" in the study.

\section{Ethnographic observations}

Participating and non-participating observations (90) were carried out to describe the end-of-life care simulation in the context of nursing education (IV). Groups of students were video- and audio- recorded during an endof-life care simulation, including the post-debriefing session. The first author took field notes when watching and listen to the recordings and additional data included a scenario template, describing the set-up of the simulation. The first author made one participant observation during one simulation session and the post-simulation debriefing.

Study IV described a simulation training where tutorial groups of nursing students were faced with three scenarios. In the scenarios, a woman (a high-fidelity manikin, called Karin) was dying from cancer. An actress played the role of Eva, Karin's mother. During the simulation, the tutor was present in the simulation room but did not participate in the session or interact with the students.

\section{Co-design, ideas groups and prototyping}

In study V, "ideas groups" and "prototyping" were used to develop the intervention as described in the in the Health Service Co-design toolkit (91). Ideas groups were used to brainstorm ideas for improvements in communication about prognosis and end-of-life care, and to produce ideas of how to implement the improvements in clinical practice. Prototyping was used to test the new improvements to see if they would work. It was also a useful way to engage and stimulate creativity among the stakeholders (patient, 
family members, health care professionals and researchers) taking part in the ideas groups (91).

\section{Feasibility testing}

To test the feasibility of some parts of the intervention, a national invitation to participate in the communication course were sent out to HF clinics in all regions in Sweden. All cardiac professionals who were interested in the content of the course were eligible to participate.

The feasibility testing of the intervention focused on two areas; acceptability and limited efficacy (92) and those areas were tested using a questionnaire that was developed for this study. Acceptability refers to the participants' satisfaction with and reactions to the intervention. This area was measured through open and closed-ended questions and statements using a 4-point Likert-type scale with the response options $1=$ strongly agree $-4=$ strongly disagree.

The limited efficacy testing evaluated how successful the intervention was with the intended users (92). This area was measured trough questions and statements that assessed the participants' knowledge, confidence and skills to discuss prognosis and end-of-life care. This was done using a 4-point Likert-type scale with the answering alternatives $1=$ strongly agree 4=strongly disagree.

The statement: "I have knowledge to discuss the following areas with a patient" assessed knowledge, whereas the statement "I feel confident and skilled to be able to discuss the following areas with a patient" assessed confidence and skills.

\section{Data analysis}

\section{Quantitative data}

The IBM Statistical Package for Social Science (SPSS) versions 20-23.0, were used to analyse quantitative data in this thesis. Descriptive statistics were used to analyse the participant's background characteristics in study I-IV. In the analysis (I-III, V), absolute numbers and percentages were computed for nominal data, means and standard deviations were calculated for continuous data. Student's t-test, Chi-square tests or Fishers' exact test were used to compare data from Sweden and the Netherlands (I) and to compare demographic characteristics between nurses in study II, who reported few or many barriers to discuss prognosis and end-of-life 
care. To analyse factors related to barriers in study I, two groups were created based on the numbers of barriers, with o-2 barriers labelled as "few" and 3-7 barriers labelled as "many". Outcomes were considered statistically significant when $\mathrm{p}<0.05$ (I-II) with Bonferroni correction for multiple testing (II). Corrections for multiple testing were not made in study I because of the explorative character of the study.

In study $\mathrm{V}$, data from questionnaires was described in frequencies and proportions, and Cronbach's alpha was used to measure the internal consistency of the questions in the test-retest.

\section{Qualitative data}

To analyse data from open-ended questions in study I-II, conventional content analysis according to Hsieh and Shannon (93) was used in study I and qualitative content analysis according to Graneheim and Lundman (94) was used in study II.

In study I+II, the analysis included a comprehensive review of the data, where the coding and the categories were derived directly from the data. Initially, all data was read through to obtain a sense of the whole. Next, meaning units from the data were condensed into codes and sorted into subcategories, depending on the relationship between the codes. After that, the subcategories were explored for underlying meaning and linked together into categories. The categories were derived from the text through analysis of the meaning of the subcategories, and by linking back to the research question. To enhance trustworthiness, each step in the analysis was discussed in the research group until consensus was reached.

In addition, in study I, keywords and phrases, derived from the data were individually and inductively categorized into barriers or facilitators by the researchers and then discussed until consensus was reached. Barriers and facilitators were then deductively sorted into categories developed from an integrative literature review on end-of-life communication (89).

In study III, a thematic analysis according to Braun \& Clarke $(95,96)$ was used. Codes and themes were inductively developed from the data, with the aim to identify and interpret patterns in the data. Data was read through for familiarization with the content, followed by a four-step process (95). In the initial step, extracts of data were labelled with a code that captured the semantic content of what the participants said or a more latent meaning in the data. Second, codes were analysed and collated into themes that captured the central organizing concept. Third, each theme was divided into sub-themes describing specific aspects of the central organizing concept of 
each theme. In the last step, in which all co-authors participated, the codes and the full data set were revisited to determine the fit of the overarching themes and the sub-themes. Coding and development of overarching themes and sub-themes were primarily conducted by the first, second and last author. The co-authors focused on the validation of the results by reading parts of the interviews and comparing the data with the suggested overarching themes and sub-themes. To enhance trustworthiness, the final analysis was discussed in the research group until consensus was reached.

To describe and evaluate the end-of-life care simulation in study IV, predetermined questions were used, focusing on the overall impression of the simulation and how the simulation method seemed to work as an educational method: How do the students act and react during the simulation? What are the students' experiences after the simulation? What do the students learn from a simulation of this complexity?

In study V, data from the ideas groups (field notes and audio-recordings) and data from the open-ended questions in the questionnaires was evaluated, discussed and summarized in the research group. As the aim was to identify improvement ideas expressed by the participants, and evaluate the intervention, the data was summarized without an in-depth qualitative analysis.

\section{Ethical considerations}

All studies followed the principles of the World Medical Association Declaration of Helsinki (World Medical Association 2013). Ethical approval was granted for all studies by the Regional Ethical Review Board in Linköping (Dnr. 2013/244-31, 2017/464-32), except for study IV where an ethical approval was not needed. In study II, the Dutch Medical Ethical Committee concluded that no additional approval was needed in the Netherlands, as no data was collected from patients or patients' medical records.

In study IV ethical approval was not needed, as nothing was done with or to the participants. All video recordings of the simulation session were standard procedure in the nursing education. The videos that were being recorded were evaluated by the researchers those. The students were not interviewed and there was no interaction with them, except for the first author attending one simulation session and the following post-debriefing session as a non-participants observer, taking field notes and making a voice recording. During the other post-debriefings, the students were alone with their tutors during the audio recordings, and they arranged with the audio recordings themselves. 
Informed consent was obtained from all participants in the studies. Participants were guaranteed confidentiality and were informed that they could end their participation at any time, without any consequences.

Discussions of prognosis and end-of-life care could possibly make patients anxious, raising many questions and concerns. The interviewer made sure to take short, informal breaks and pauses during the interviews so that the patients could relax and think of something else for a moment when the conversation became difficult or sensitive. One way of pausing could be to give some attention to the patient's dog and play with it for some time before continuing with the interview. A contact person (an experienced $\mathrm{HF}$ nurse) was available by telephone if the patients in study III wanted to talk to someone after the interviews. The patients were also encouraged to discuss any questions that arose during the interviews with their physician/nurse for further information.

The participants in the focus group interviews in study III all agreed that what was discussed during the interview should not be shared elsewhere. This was a way of trying to protect the integrity of the participants.

In study I-II and V, it was emphasized in the study information to the participants that they were welcome to contact the researcher at any point if they had questions or concerns. In study IV, the students were instructed to talk to their supervisors if they needed support. The educational program also had their own procedures for student support after the simulation training.

Before the simulation in study IV, the students were informed by the instructor that they would not be graded or evaluated in the study. If a student did not want to be part of the study, they could contact the researchers. The palliative simulation was a challenging learning situation for many of the students. The post-debriefings were one way for students to process and deal with feelings and thoughts that had surfaced due to the simulation sessions.

The first author prepared for the interviews by discussing with an experienced supervisor about interview techniques, own pre-understanding of the subject, feelings and thoughts. A pilot-interview with a HF patient was also performed where the supervisor also participated and supported the first author in the interviewing and gave advice afterwards on how to improve the interview technique.

The patients in study III could choose the place for the interview. Most preferred to be in their own homes, a well-known environment for them. Only one participant wanted to be interviewed at the local university. 
Before the interview started, the researcher used small talk to make the participant feel safe and relaxed and thereby establishing a good connection.

Talking about the HF trajectory was often a sensitive topic, and it was a delicate task for the researcher to be sensitive enough to the participant's reactions and know when to ask an extra question, when to make a pause, or let some things be. However, to obtain in-depth information from the participants and really have a conversation with them, it was also important to be curious and brave enough to ask questions that were more difficult to discuss.

To really meet another person, Astrid Seeberger argues that one has to be "shamelessly" curious about that person's feelings and thoughts. To be shamelessly curious of other persons can be of great value when interviewing them, and it also means not to be ashamed of being curious or to be ashamed of the things that people tell you (97). Another thing Seeberger emphasizes is the importance of being totally present, focusing on the person that you are talking to.

Bearing this in mind, the researcher tried to be brave and curious and ask questions that were also difficult to ask, and then be totally present, focusing on the stories that were told. The researcher established a good contact with all participants. With some, there was an extra deep understanding, even though they had just met. One participant said that "I was afraid to talk about these issues, I was nervous before you came here. But now you are here and it is going so well, it is easy to talk to you I feel that you understand". 


\section{RESULTS}

\section{Study participants}

In this thesis, data have been collected in health care professionals (nurses and physicians) from Sweden and The Netherlands (nurses only), HF patients from Sweden and The Netherlands, family members and nursing students from Sweden.

In study I, 111 Swedish HF nurses participated who had dedicated time to work with HF patients. Of those the majority were women (94\%) with a mean age of 51 years. Those 111 nurses also participated in study II, plus 2 more nurses, ending up in a total of 113 nurses participating in study II. Additionally, 166 Dutch HF nurses participated in study II, making the total amount of participants in study II, 279. Most of the nurses in both countries were women (90 \%), but the Swedish nurses were slightly older than the Dutch nurses, (51-9 versus 49-8, $\mathrm{p}=0.038)$. The Swedish nurses in study II collected data on 611 Swedish HF patients, and the Dutch nurses collected data on 1198 Dutch HF patients. The mean age of the patients was $71 \pm 12$, and the majority (62\%) were men.

The participants in study III were 24 HF patients, including $75 \%$ men, with an age range between 52-87 years. In study IV, the participants included approximately 60 nursing students where the majority of the students were women between 20-30 years of age.

Study V was performed in two phases and included different participants in each phase. In the development phase of the intervention, $9 \mathrm{HF}$ patients (mean age of 75 years), 2 family members (mean age of 70 years), and 9 health care professionals (mean age of 50 years) from HF-, and palliative care participated. In the testing phase of the intervention, 16 female health care professionals participated, with a mean age of 39 years. 


\section{Table 2. Overview of participants in the studies}

\begin{tabular}{|c|c|c|c|c|c|c|}
\hline & Study 1 & & & Study 3 & Study 4 & Study 5 \\
\hline Participants & $\begin{array}{l}\text { Nurses } \\
\mathrm{N}=111\end{array}$ & $\begin{array}{l}\text { Swedish nurses: } \\
\mathrm{n}=113 \\
\text { Dutch nurses: } \\
\mathrm{n}=166 \\
\mathrm{~N}=279\end{array}$ & $\begin{array}{l}\text { Swedish patients } \\
n=611 \\
\text { Dutch patients } \\
n=1198 \\
N=1809\end{array}$ & $\begin{array}{c}\text { Patients } \\
N=24\end{array}$ & $\begin{array}{c}\text { Nursing } \\
\text { students } \\
\sim 60\end{array}$ & $\begin{array}{l}\text { Phase 1: } \\
9 \text { patients } \\
2 \text { family members } \\
9 \text { professionals } \\
\text { Phase } 2 \text { : } \\
16 \text { professionals }\end{array}$ \\
\hline Female, $\mathrm{n}(\%)$ & $\begin{array}{l}104 \\
(94 \%)\end{array}$ & $\begin{array}{l}\text { Swedish nurses } \\
106(94 \%) \\
\text { Dutch nurses } \\
145(87 \%)\end{array}$ & $\begin{array}{l}\text { Swedish patients } \\
197(32 \%) \\
\text { Dutch patients } \\
505(42 \%)\end{array}$ & $6(25 \%)$ & $\begin{array}{l}\text { Majority } \\
\text { females }\end{array}$ & $\begin{array}{l}\text { Phase } 1 \text { : } \\
2 \text { patients }(22 \%) \\
2 \text { family members }(100 \%) \\
9 \text { professionals }(100 \%) \\
\text { Phase } 2 \text { : } \\
16 \text { professionals }(100 \%)\end{array}$ \\
\hline Age, mean/years $\pm S D$ & $51 \pm 9$ & $\begin{array}{l}\text { Swedish nurses } \\
51 \pm 9 \\
\text { Dutch nurses } \\
49 \pm 8\end{array}$ & $\begin{array}{l}\text { Swedish patients } \\
72 \pm 11 \\
\text { Dutch patients } \\
72 \pm 12\end{array}$ & $52-87 \pm 73$ & $20-30$ & $\begin{array}{l}\text { Phase 1: } \\
\text { Patients mean age } 75 \text { years } \\
\text { Family members mean age } \\
70 \text { years } \\
\text { Professionals mean age } 50 \\
\text { years } \\
\text { Phase } 2 \text { : } \\
24-57 \pm 39\end{array}$ \\
\hline NYHA class & - & $\begin{array}{l}\text { Swedish patients } \\
\text { I } 53(9 \%) \\
\text { II } 284(49 \%) \\
\text { III } 223(39 \%) \\
\text { IV } 15(3 \%)\end{array}$ & $\begin{array}{l}\text { Dutch patients } \\
\text { I } 101(9 \%) \\
\text { II } 495(45 \%) \\
\text { III } 431(40 \%) \\
\text { IV } 63(6 \%)\end{array}$ & $\begin{array}{l}\text { I } 5(21 \%) \\
\text { II } 10(42 \%) \\
\text { III } 9(37 \%) \\
\text { IV } 0(0 \%)\end{array}$ & - & - \\
\hline $\begin{array}{l}\text { NT-proBNP median, (IQR) } \\
\text { BNP }\end{array}$ & & $\begin{array}{l}\text { Swedish patients } \\
1970(3687) \\
498(87)\end{array}$ & $\begin{array}{l}\text { Dutch patients } \\
\text { - }\end{array}$ & - & - & - \\
\hline $\begin{array}{l}\text { Comorbid diseases } \\
\text { Endocrinology } n(\%) \\
\text { Respiratory/lung } \\
\text { Musculoskeletal } \\
\text { Cancer } \\
\text { Renal disease } \\
\text { Psychiatric } \\
\text { Gastrointestinal } \\
\text { Other* }\end{array}$ & - & $\begin{array}{l}129(4 \%) \\
86(19 \%) \\
58(13 \%) \\
50(11 \%) \\
32(7 \%) \\
25(6 \%) \\
5(6 \%) \\
46(10 \%)\end{array}$ & - & - & - & - \\
\hline ICD/CRT n, (\%) & - & - & - & $9(34 \%)$ & - & - \\
\hline $\begin{array}{l}\text { Years working in HF care } \\
\text { years } \pm S D\end{array}$ & $40 \pm 12$ & $\begin{array}{l}\text { Swedish nurses }= \\
40 \pm 12\end{array}$ & $\begin{array}{l}\text { Dutch nurses }= \\
35 \pm 9\end{array}$ & - & - & $\begin{array}{l}\text { Phase 2: } \\
0-25 \pm 9\end{array}$ \\
\hline
\end{tabular}

Abbreviations: NYHA class; New York Heart Association functional class; NT-pro BNP, N-terminal pro-Brain Natriuretic Peptide; BNP, Brain Natriuretic Peptide; ICD, Implantable Cardioverter Defibrillator; CRT, Cardiac Resynchronization Therapy. ${ }^{*}$ Others include haematology, neurology, infections, skin disease, lupus and liver disease. 


\section{HF nurses' perspective on communication about prognosis and end-of-life care}

Most of the Swedish HF nurses had discussed prognosis (96\%) and end-oflife care (84\%) with a HF patient at some point in clinical practice (I).

The nurses often reported that a physician had the main responsible for such discussions (69\%), but that the nurse also had a role to play. Nurses encounter patients more often than physicians and could be the ones identifying the need for a conversation about the prognosis and end-of-life care.

Most nurses reported to having enough knowledge to be able to answer most questions patients could have about prognosis (97\%) and end-of-life care (83\%). However, more than half of the nurses (55\%) reported that they often or sometimes hesitated to discuss prognosis in daily practice, and $58 \%$ reported that they the same regarding end-of-life care. This hesitation was reported to be due to not knowing how to answer the patient. The majority of the nurses (84\%) reported that patients might become worried if they initiated discussions about prognosis, and $84 \%$ described the same regarding end-of-life care. Many nurses (55\%) were also concerned that the patient would be upset if the nurse discussed prognosis and 62\% reported the same thing regarding end-of-life care.

In the analysis of the qualitative data (I), it was discovered that prognosis and end-of-life care discussions were guided by clinical routines. Thus, nurses discuss these topics mainly when the patient is believed to be approaching the end-of-life or when there are worsening HF symptoms. The discussions should be tailored to the specific patient's situation, other matters could often be of more importance, such as improving self-care and adherence to treatment. The discussions could be held when the patient initiated a conversation and asked questions themselves. Prognosis and end-of-life care discussions were also directed by the professionals 'responsibilities. Some nurses did not perceive these discussions to be a part of their role as a nurse (II). 
Based on literature reviews $(53,98)$, barriers for communication were suggested for the nurses to agree/not agree on (I).

\begin{tabular}{|l|c|}
\hline \multicolumn{2}{|c|}{$\begin{array}{c}\text { Table 3. Barriers for communication about prognosis and end-of-life } \\
\text { care (N=111) }\end{array}$} \\
\hline Heart failure has an unpredictable trajectory & $81(77 \%)$ \\
\hline The patient has a high rate of comorbidity & $66(62 \%)$ \\
\hline $\begin{array}{l}\text { The patient has a general impaired condition } \\
\text { with, e.g., fatigue and cognitive impairment }\end{array}$ & $66(62 \%)$ \\
\hline Fear of taking away the patient's hope & $65(62 \%)$ \\
\hline Inadequate time for communication & $57(52 \%)$ \\
\hline $\begin{array}{l}\text { Not knowing how to talk and discuss with } \\
\text { the patient }\end{array}$ & $31(30 \%)$ \\
\hline Lack of communication skills & $19(18 \%)$ \\
\hline
\end{tabular}

When comparing nurses who reported few barriers $(n=29)$ with nurses who reported many $(n=81)$, it was found that the nurses who reported few barriers more often stated that it was appropriate for them as nurses to initiate a discussion about prognosis $(93 \%, p<0.05)$ and end-of-life care $(83 \%$, $p<0.01$ ) with HF patients, compared to nurses who reported many barriers (74\% and 54\%). Nurses who reported many barriers also more often stated that they had no or little knowledge $(78 \%, p<0.05)$ on discussing prognosis and end-of-life care $(93 \%, p<0.01)$, compared to nurses who reported fewer barriers (55\% and $72 \%$ ). Nurses who reported many barriers were also more hesitant to initiate discussions about end-of-life care because they did not know what to answer (70\% vs. $25 \%, p<0.001)$. The nurses who reported many barriers also more often stated that HF patients would be worried if they initiated a discussion about end-of-life care (90\% vs. 69\%, $p<0.05$ ).

\section{Practice of discussing prognosis and end-of-life care in a patient education context}

Prognosis and end-of-life care were (together with sexual activity) the three least frequently discussed topics in HF clinics in both Sweden and the Netherlands (II). In conversations with 1,809 Swedish and Dutch HF patients, prognosis was discussed with $38 \%$ of the patients and end-of-life care was discussed with $10 \%$ of the patients. 


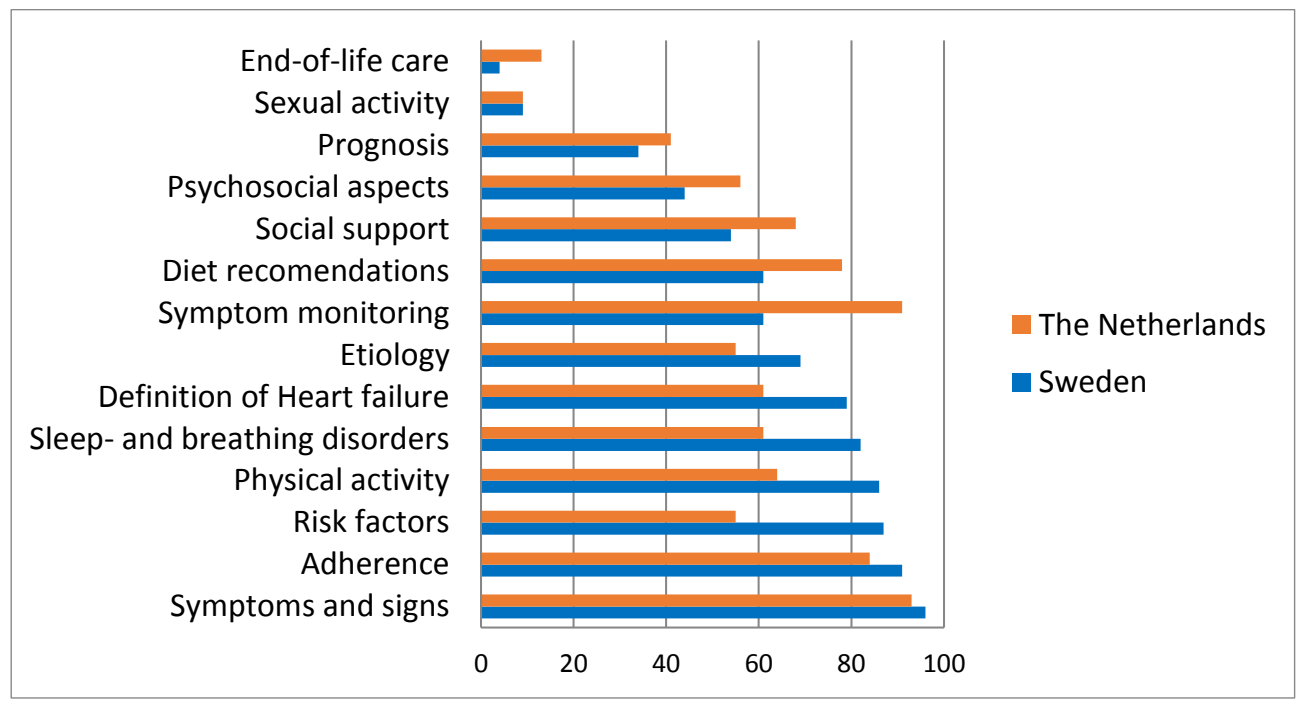

Figure 2. Topics discussed at HF clinics in Sweden and the Netherlands.

For the $62 \%$ of patients with whom prognosis was not discussed, nurses reported that this could be relevant to discuss in the future in $70 \%$ of the patients. Similarly, for the $90 \%$ of patients with whom end-of-life care was not discussed, the nurses reported that it could be relevant to discuss this topic later on in $75 \%$ of the patients. The Swedish nurses discussed on average $9 \pm 3$ topics with the patients during a HF clinic visit, and the Dutch nurses on average $8 \pm 3$ topics $(t=2,96, p=0.003)$. Prognosis were more often discussed with the Dutch patients compared to the patients in Sweden ( $41 \%$ vs. $34 \%$, p <0.001). A significant difference was also observed in conversations about and end-of-life care ( $13 \%$ vs. $4 \%, \mathrm{p}<0.001)$. In addition, the Swedish nurses more often reported that it was not at all relevant to discuss prognosis with the patient (11\% vs. $5 \%, \mathrm{p}<0.001)$ and end-of-life care (22\% vs. $7 \%, \mathrm{p}<0.001$ ), while the Dutch nurses to a greater extent described that prognosis and end-of-life care should be discussed as soon as possible (27\% vs. $20 \%$, p<0.001, $13 \%$ vs. $5 \%$, p<0.001) (II).

\section{Patients' perceptions of prognosis communication}

Patients expressed different experiences of and preferences for communication about their HF prognosis (III). 


\section{Overarching theme 1: The message sent}

Many patients described that the professionals had not provided them with any prognosis information at all. The communication with health care professionals mostly focused on the treatment and management of HF. Some professionals had given the patients a very optimistic view of a life with HF. They had glorified the prognosis, telling the patients that HF would just make them feel a little worse. In contrast, other patients had been given a very bad prognosis, describing the worst-case scenario. Professionals had talked about all those who had died from HF, giving the impression that the patients would definitively die from HF. However, in some situations, professionals had given the patients information about the prognosis to an extent and in a way that they thought was perfect for them to handle, and in accordance with their preferences. Patients expressed that the professionals had understood how much information about the prognosis they wanted to hear and then provided that information, sometimes in a quite straightforward manner.

\section{Overarching theme 2: Hoping for the best or preparing for the worst}

The patients had different understandings of $\mathrm{HF}$ as a chronic illness, which had an impact on their preferences for communication about the prognosis. Some patients preferred to avoid thinking about their HF prognosis because they did not want to lose hope about the future. They lived one day at a time, focusing on the here and now, wanting to forget about the illness altogether. The patients knew that they had HF, but they did not have the understanding that HF might lead to their death.

Other patients were ambivalent in their approach towards discussing prognosis. They wanted to know the truth about their prognosis, but at the same time they did not want to know anything as they feared that they might hear something they did not want to hear. These patients only wanted to receive "good" and positive information from the professionals, as they perceived such information to be something that they could benefit from.

There were also patients who wanted to know the objective and absolute truth about their prognosis, and who were afraid to live under false expectations. For these patients, the truth about their prognosis was that they might die because of their illness. Even though the truth may hurt, they believed that knowing the truth was necessary to live as good a life as possible. 


\section{Simulation training in end-of-life care communica- tion}

End-of-life care simulations can be used as a teaching innovation, learning nursing students about end-of-life care and communication skills in challenging situations (IV). The students participated in a nursing education program using the method Problem-Based learning (PBL). Traditional lectures were mixed with student tutorial groups and supportive learning elements, such as training in simulated "real-life" situations using simulated patients and family members. The simulation described in this study was part of an end-of-life care simulation during the last term of the 3-year bachelor's degree level nursing program. At this point, the students learn and practice basic palliative care, something that they are expected to be able to handle as nurses.

Table 4. Learning goals of the end-of-life care simulation

\begin{tabular}{|l|l|}
\hline $\begin{array}{c}\text { Medical knowledge and } \\
\text { competencies }\end{array}$ & \multicolumn{1}{c|}{ Communication } \\
\hline $\begin{array}{l}\text { Manage patients' and their fami- } \\
\text { lies' reactions to bad news in a } \\
\text { professional manner }\end{array}$ & $\begin{array}{l}\text { Apply a professional approach to } \\
\text { patients and families based on } \\
\text { ethical reasoning }\end{array}$ \\
- Assess and provide symptom re- & - $\begin{array}{l}\text { Identify and consider the spir- } \\
\text { itual and existential needs asso- } \\
\text { ciaf for patients with partially or } \\
\text { completely compensated self- } \\
\text { care needs when opportunities } \\
\text { for curative care are missing }\end{array}$ \\
$\begin{array}{l}\text { Apply a professional approach in } \\
\text { relation to patients, families and } \\
\text { other health care professionals }\end{array}$ \\
\hline
\end{tabular}




\section{Table 5. Overview of the scenarios and the post-simulation debriefing}

\section{Scenario 1}

The students met Karin in her home. She was lying in bed wearing a long T-shirt, underwear, trousers and a scarf around her head. She had a stoma and a subcutaneous port-a-cath. She had terminal cancer and was expected to die soon. The simulation room was decorated as a home with furniture, flowers, photos, candles and books. Karin lay in bed and, in some simulation sessions, her partner Petra/Peter, aged 28 (played by a student), sat next to her on the bed. Karin was in a lot of pain and worried about her son, Erik, aged 16 , who seemed to avoid visiting her. Her partner felt powerless and worried about their financial situation.

\section{Scenario 2}

In this scenario, Karin was alone and very tired. She had no appetite and had sores in her mouth. She was worrying about the upcoming birthday of her daughter Olivia, aged 13. Karin wanted to bake a cake as she would usually do, and she also wanted to be able to eat some cake in order to give Olivia a good feeling about her birthday. In this scenario, Karin talked more about her concerns for the family and she asked what her final hours in life would be like.

\section{Scenario 3}

This scenario took place one week after the first scenario. Karin had died a few minutes before and her mother Eva was in the room next door. Eva had many questions and wondered what would now happen now with Karin's body, children, etc. Eva also had a lot of questions about what would happen after Karin's death. Who would take care of the funeral? Who would tell the children that their mother had died? Who would call time of death?

\section{Post-simulation debriefing}

Directly after the third scenario had ended, the students met with their tutor in a meeting room. They sat down to debrief and discuss the simulation, how it went, and possible areas for improvement. The tutor guided the discussion and made sure to return to the learning goals of the simulation. Important learning areas to discuss included: end-of-life-care, ethics, maintaining a holistic approach, symptom and pain analysis, food and drink, family support, powerlessness, practical issues in the team, procedures of the death, the nursing process, keeping a professional approach in the home environment, other health care professionals and different religious views on death. 
When observing the students, it was discovered that some students were a bit uneasy at the beginning of the simulation, but after some time they became more relaxed and started to talk more freely with Karin. Regarding Karin's worries about her son, the students were very focused on finding practical solutions, such as offering to talk to her son, organizing a family meeting, or involving a social worker. The students tried to find good solutions for Karin's practical issues, such as how to help her take part in the baking of a birthday cake for her daughter's birthday. Many students were compassionate and caring towards Eva. They asked her how she felt and tried to comfort her. They sat down with her at the table, some holding her hand. The students felt that the end-of-life care simulation was a good opportunity to practice handling end-of- life situations as it gave them a chance to experience this situation and their own feelings and thoughts on death and dying.

\section{Intervention to improve communication}

In study $\mathrm{V}$, an intervention to improve communication about prognosis and end-of-life care in HF care was developed and some areas of feasibility were tested. In the development process. HF patients, their families and health care professionals working in HF care or palliative care participated. Health care professionals (nurses and physicians) participated in the following feasibility testing of the intervention.

In the development of the intervention, a co-design process was used. The future users of the intervention took part in ideas groups to suggest ways of improving communication and further prototype the suggested ideas. Two ideas were suggested and developed into prototypes, a Question Prompt List (QPL) and a communication course. Together, those two components formed the intervention.

\section{The Question Prompt List for patients and their family mem- bers}

The QPL (appendix 1) was designed to stimulate and facilitate patient and family member communication about the HF trajectory with a health care professional. The QPL is a 7-page A4 booklet in a paper format, containing 45 questions grouped into topics including:

1) Heart failure and what to expect in the future

2) Help and support during deterioration

3) End-of-life care issues 
4) Additional questions for the family members

5) Additional questions for the person who has an ICD/CRT/PM.

\section{The communication course for health care professionals}

The communication course (appendix 2) was web-based with one practical training day. The course included the following teaching methods:

- Individual tasks (online)

- Lectures (online)

- Simulation training (live)

- Group discussions (live).

The course was based on adult learning principles, using self-directed learning (99). According to Knowles (1978), the adult learner needs capacity to self-direct, identify and organize the learning around a life problem (99). The curriculum of the course was problem-centred oriented, aiming to show the participant "a problem" in clinical practice that he/she needs to solve. This should facilitate a self-directed learning process where the participant learns because "they need to", because there is a problem to solve.

To set up learning goals for the course, Bloom's Taxonomy of Educational Objectives was used as inspiration. The framework includes different levels of knowledge, stating what an individual is expected to have learnt as a result of instruction: 1. Remember (facts) 2. Understand 3. Apply 4. Analyse 5. Evaluate 6. Create (100).

\section{Learning goals of the course:}

- Understand the importance of discussing the HF trajectory and end-of-life care with patient and family, using an individualized approach

- Understand how barriers and facilitators can impact patients' and family members' reactions and preferences for communication about the HF trajectory and end-of-life care

- Reflect on own possible emotional difficulties in communication situations and plan for how to deal with such issues

- Gain knowledge on how to discuss the HF trajectory and end-oflife care with patients and family using an individualized approach 
- Develop and demonstrate skills for selecting and using appropriate communication strategies in each specific communication situation, based on the individual needs of the patient and the family members

- Demonstrate skills, knowledge and confidence about discussing the questions listed in the QPL with patients and family, focusing on their needs and specific situation.

The QPL was an important tool in the course and the participants were expected to gain the knowledge, confidence and skills required to be able to discuss the questions in the QPL with patients and family members. Another important part of the course was the practical training with simulated patients (actors) and family members (volunteer course participants), where the participants practiced using the QPL in a simulated conversation.

\section{Result of the testing of the intervention}

To test the intervention in study $\mathrm{V}$, health care professionals from cardiac care were invited to take the course.

\section{Response to the invitation}

Twenty-one cardiac professionals signed up for the course, three physicians (females, mean age $=40$ years), and nineteen nurses (females, mean age $=39$ years) from different regions in the south of Sweden. Before the course started and during the first few weeks of the course, six participants (all nurses) dropped out due to changes in their work situation or private matters. Sixteen participants attended the training day and of these, thirteen participants completed all the individual tasks and finalized the course. Some participants needed 1-2 weeks extra to be able to complete the final task. None of the three physicians finalized the last task of the course (using the Question Prompt List in clinical care with one patient and/or a family member), for reasons not known. As the physicians did not finalize all tasks, they were not invited to participate in the second round of the assessment of knowledge, confidence and skills to discuss the topics in the QPL.

\section{Feasibility testing}

Overall, in the evaluation of the course, the nurses who finalized the course were satisfied with the content of the course and how it was delivered. They reported that meeting colleagues to discuss and learn from each other as 
well as practicing conversations with simulated patients and family members during the training day was valuable. After using the QPL in clinical practice most reported that the QPL would be useful in future clinical conversations.

The majority of the participants perceived that the online lectures and the group discussions during the training day had been useful for their learning. The individual tasks 1-3 were more difficult to perform, particularly task 3, but most participants still considered the tasks to be useful for their learning. All participants took the course while working clinically, which worked well. Several of them were given time off to work with the online course at home. The participants expressed that they had gained more knowledge about communication about the HF trajectory and end-of-life care in HF. They expressed that the course had helped them to reflect on their own professional role in discussions, which made them feel more confident in discussions without feeling afraid that they would not provide the "correct" answers to patients and family. The participants believed that the course would be of huge value in future conversations with patients and family. Many of them expressed that they now felt "braver" about taking on even the more difficult conversations, asking the patients and family about their thoughts and concerns about the future. In the course group discussions, they learnt from each other, and lectures provided ideas on useful phrases to use when initiating a conversation about the HF trajectory. Most participants were satisfied with the content of the course and how it was delivered, but some would have liked to have one more face-to-face training day as a follow-up. Several of them also asked if it was possible for them to share the online lectures with colleagues and spread the information. Most of the participants had no technical problems with the website but three participants reported difficulties to view one of the lectures. All were very positive about recommending the course to a colleague.

The majority of the participants used the QPL in clinical practice with one patient and/or a family member during the course. Most of them (79\%) reported that the QPL will be useful in future clinical conversations with patients and family members. However, there were suggestions for improvements in the QPL, such as shortening the number of questions and merging some questions with a similar content.

Most of the participants increased knowledge, confidence and skills to discuss most questions in the QPL (Figure 3-7). However, the participants reported that after the course they had to have less knowledge, confidence and skills to discuss two of the questions in part 2 of the questionnaire (Figure 4). These concerned who the patient/family member can talk to about 
the things that worry them. The greatest differences pre and post testing in knowledge, confidence and skills were reported in part 5 , where the questions concerned ICD/CRT/PM (Figure 7).

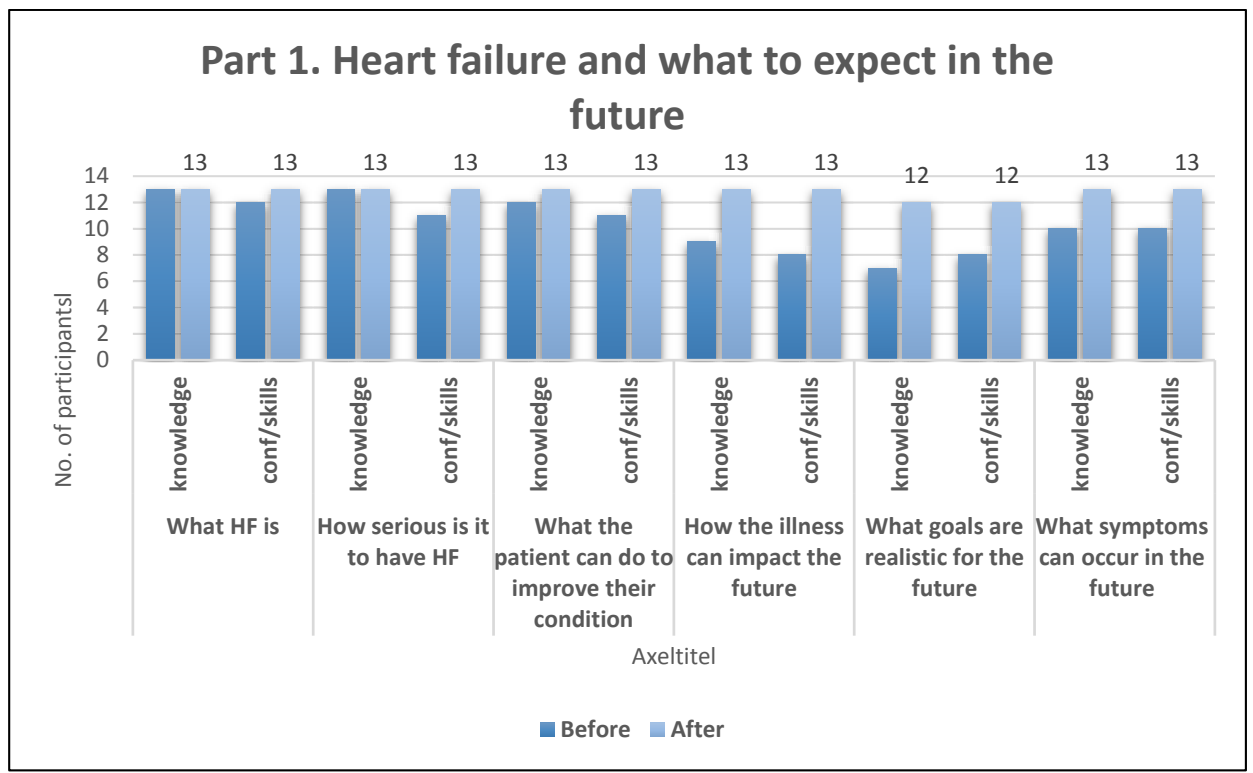

Figure 3. The number of participants agreeing (strongly agree/agree) to have the knowledge/confidence/skills to discuss the questions in part 1 of the QPL, before and after the course, $\mathrm{N}=13$. Abbreviation: $\mathrm{HF}$, Heart failure.

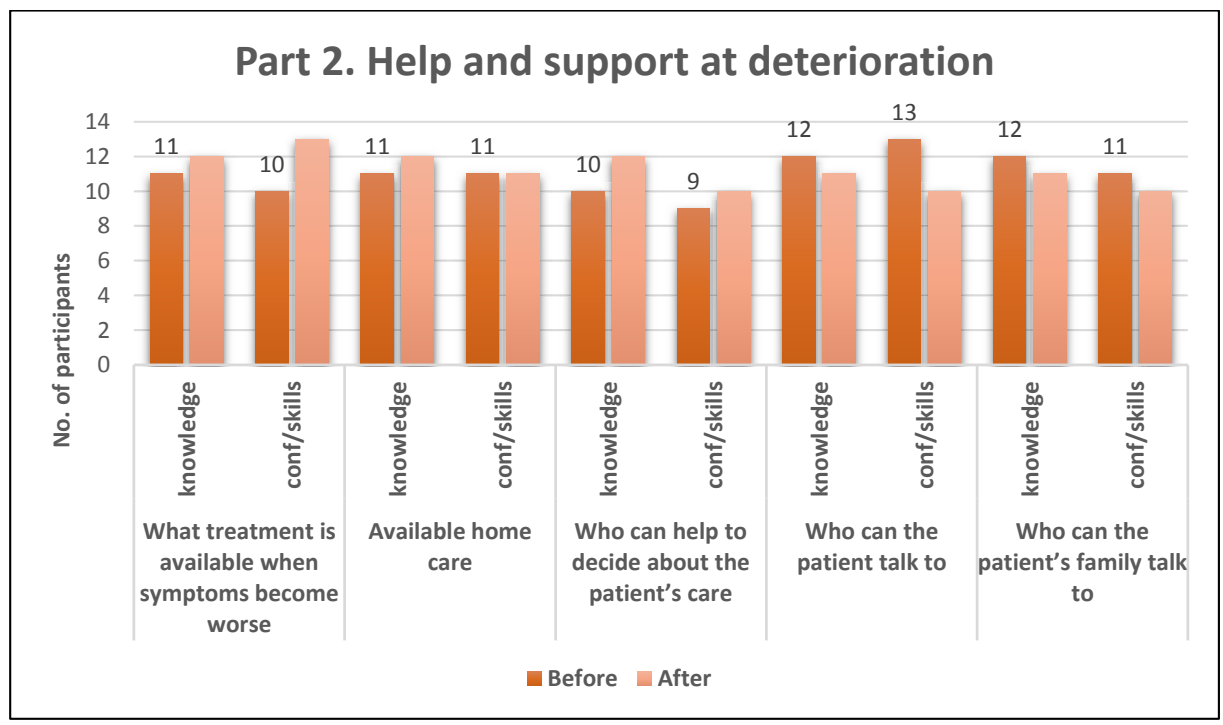

Figure 4. The number of participants agreeing (strongly agree/agree) to have the knowledge/confidence/skills to discuss the questions in part 3 of the QPL, before and after the course, $\mathrm{N}=13$. 


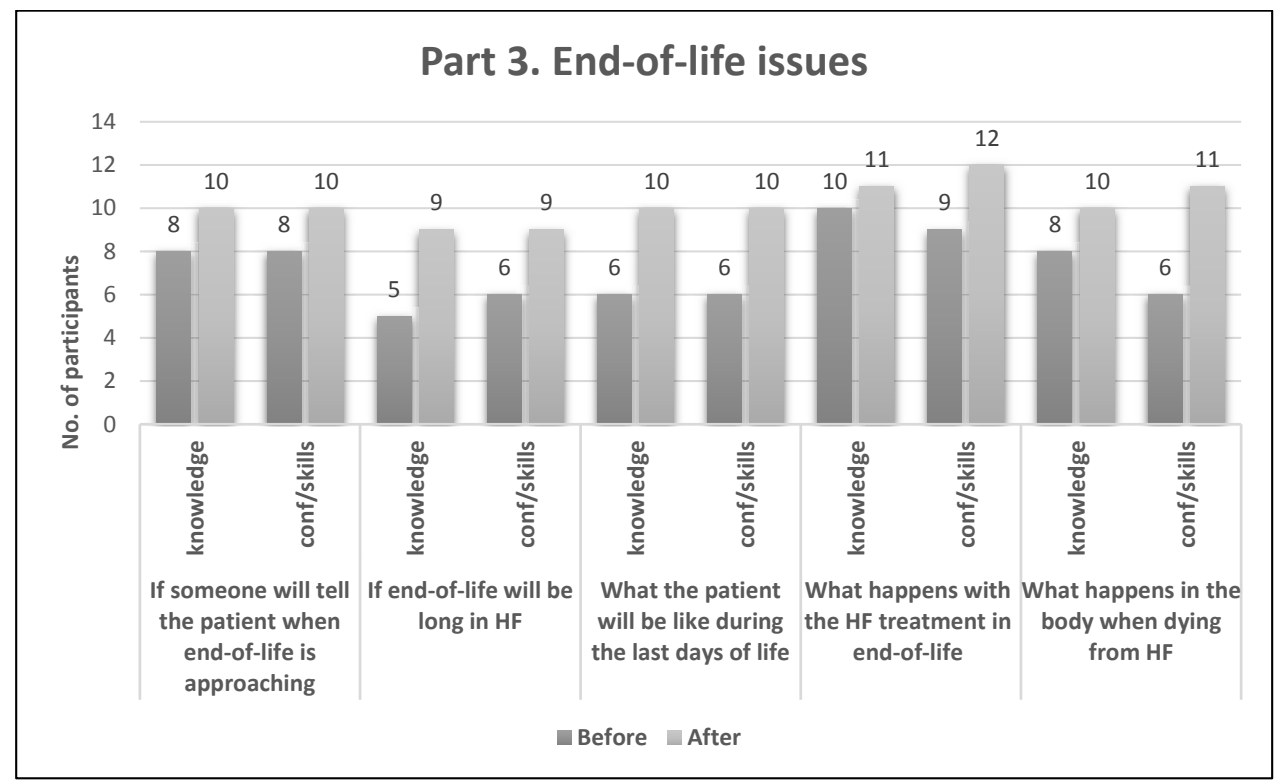

Figure 5. The number of participants agreeing (strongly agree/agree) to have the knowledge/confidence/skills to discuss the questions in part 2 of the QPL, before and after the course, $\mathrm{N}=13$. Abbreviation: $\mathrm{HF}$, Heart failure.

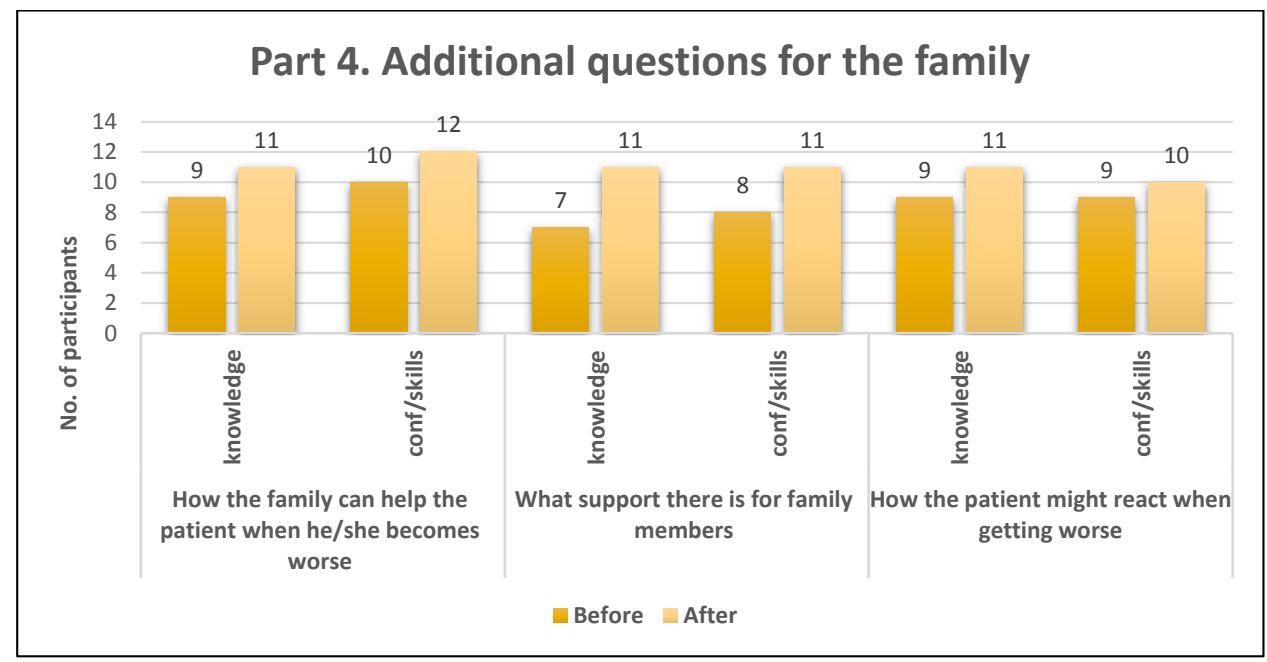

Figure 6. The number of participants agreeing (strongly agree/agree) to have the knowledge/confidence/skills to discuss the questions in part 4 of the QPL, before and after the course, $\mathrm{N}=13$. 


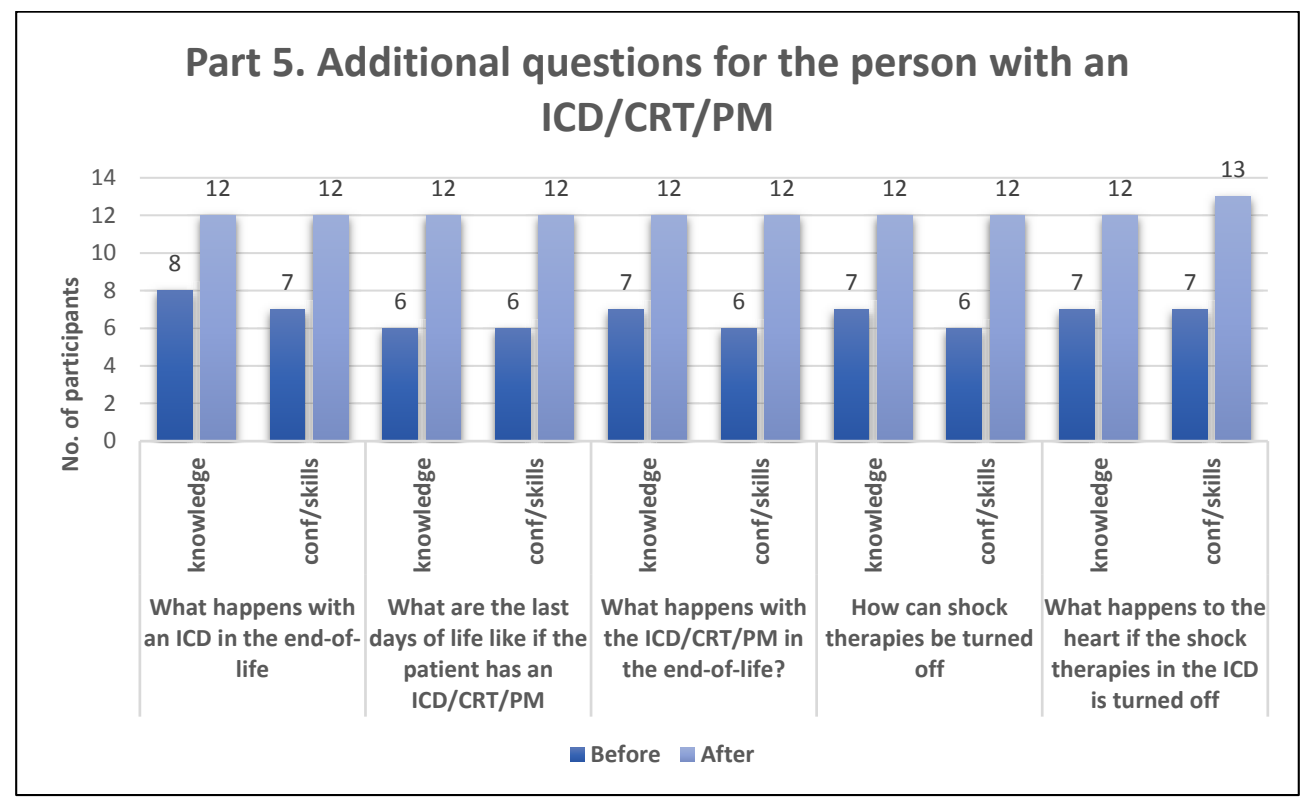

Figure 7. The number of participants agreeing (strongly agree/agree) to have the knowledge/confidence/skills to the discuss questions in part 5 of the QPL, before and after the course, $\mathrm{N}=13$. Abbreviations: ICD, Implantable Cardioverter Defibrillator; CRT, Cardiac Resynchronisation Therapy; PM, Pacemaker. 


\section{DISCUSSION}

The overall aim of this thesis was to improve communication about the heart failure trajectory in patients, their families, and health care professionals.

But why should health care professionals discuss the HF trajectory and end-of-life care with patients and their families? Who should discuss these topics, and when and where should they be discussed? How are the topics discussed in current health care? Does the communication need to be improved, and if that is the case, how?

This thesis strives to answers these questions. The articles included in this thesis gives health care professionals, patients and their families a voice and involves them into becoming important contributors in finding answers to the questions mentioned above.

\section{Terms and concepts}

\section{Prognosis and end-of-life care versus HF trajectory}

The terms "prognosis" and "end-of-life care" were difficult to use in some cases. Afterwards, it seemed as if the studies were started using the wrong wordings. Health care professionals seemed to think about the term "prognosis" as the definition of the amount of time that the patient had left to live, which was never intended in this thesis. Therefore, the word "trajectory" was instead used to describe the expected time course of the illness in a specific individual. The HF trajectory starts when the patient receives their diagnosis and ends when the patient dies. Discussions about the HF trajectory can relate to any issue related to the HF diagnosis, from discussing symptoms to decisions on deactivation of devices at the end-of-life. Because of this change in wording, the terms "illness trajectory" or "HF trajectory" are used in this thesis, instead of "prognosis". Similarly, "end-oflife care" can be incorporated in "HF trajectory" and in the discussion of this thesis, "HF trajectory" will mostly be used instead of "prognosis" and "end-of-life care". 


\section{Palliative care versus palliative care approach}

At the start of this thesis, the focus was on the lack of palliative care in HF care, even though there were guidelines and consensus papers both in Europe and other parts of the world, emphasizing the possible need for palliative care in the HF population (15-17). In study I-III it was stated that patients and families might need to discuss the prognosis and end-of-life care as a way for health care professionals to assess possible palliative care needs.

However, during the last phase of working with this thesis, terms and wording were discussed. First, it was discussed if the term "palliative care" is the most suitable term in our research that focuses on communication about the HF trajectory, with the aim to improve such communication in HF care. Of course, it can be argued that all HF care includes palliative care, regardless of context of care, as only palliation is possible for HF symptoms. Some years ago, the Canadian Hospice Palliative Care Association defined an alternative term to palliative care, to be used in people living with a chronic, life-limiting illness, namely the "palliative care approach". This integrated palliative care can be provided by primary care throughout the illness trajectory. In this palliative care approach, open and sensitive communication about the HF trajectory is an important focus of the care, giving patients and families the possibility to be truly informed and involved in the care (101). This term might be more useful in future research, describing the type of care professionals need to provide in HF care in order to meet the multidimensional needs of patients and their families (102).

\section{Heart failure nurses' perceptions of communica- tion about the HF trajectory}

\section{Practice and responsibility}

Most of the 111 nurses who participated in study I reported that physicians should have the main responsibility for discussing prognosis and end-oflife care but could also see themselves as playing an important role in such communications.

Most nurses had at some point discussed prognosis and end-of-life care in clinical practice and felt knowledgeable about these discussions. However, many also reported a need for further training and acknowledged that there are barriers for communication, including the unpredictable trajectory of $\mathrm{HF}$, patients' comorbidities and the opinion that patients in NYHA class IIIII are not in the end-of-life. 
The nurses had ambiguous attitudes towards their role in discussing prognosis and end-of-life care and often hesitated to initiate such conversations with patients. This hesitation might be due to the feeling that a physician should have the main responsibility of the discussions, as well as perceived barriers for communication.

However, nurses have an important role in the management of HF patients in nurse-led HF clinics (24), and they could take more responsibility for these conversations as a part of delivering basic palliative care. The HF nurses provide care according to guidelines, optimize medications and educate patients about the importance of self-care, including symptom monitoring and possible life-style changes. The care could also see to needs for psychosocial support in both the patient and their family (24). Within this HF care context, discussions about the HF trajectory are suitable, but perceived barriers for communication seem to hinder these discussions taking place.

To overcome the perceived barriers, it could be useful to look at the facilitators for communication proposed by the nurses (I). On an organizational level, standardization of communication was suggested, together with sufficient time to discuss with patients and their families. Facilitators related to the profession entailed the need for communication training and functioning teamwork. The nurses mentioned that if a physician had already had a break-point conversation with the patient and the family, it became easier for the nurse to discuss prognosis and end-of-life care. However, according to the literature $(15,39)$, communication about the HF trajectory can start even when the patient receives their HF diagnosis. Thus, nurses need to be prepared for these discussions long before a break-point conversation takes place. Some facilitators were disease-specific. For example, it was easier for the nurses to discuss the HF trajectory if there was a deterioration in the HF, or if the patient was scheduled for a device implantation. Other facilitating factors were if the patient and the family had an open attitude and asked questions about the HF trajectory.

Guidelines (15) have suggested that it is important that health care professionals have an open and honest communication in discussions about the $\mathrm{HF}$ trajectory and preferences for future end-of-life care with HF patients and families. This approach can be translated to an open awareness context (54), where professionals in HF care should openly discuss the HF trajectory and options for end-of-life care with HF patients (53). The patient and their family members need to understand the unpredictability of the HF trajectory in order to be involved in the care, make choices, plan for the future and prepare for end-of-life $(13,103)$. In communication about the 
HF trajectory, professionals need to focus on each individual's needs and preferences for the information they want and how to receive it. A personcentred care (104) approach and a patient-centred communication (105) are two concepts that can guide such communication in accordance with the patient's and the family members' preferences.

\section{Cultural aspects related to communication}

Sweden and the Netherlands are two countries with a long history of managing patients in nurse-led HF clinics. However, in both Sweden and the Netherlands, the prevalence of discussing prognosis and end-of-life care was surprisingly low, considering that these are topics described in current guidelines as important to discuss. The Dutch nurses more often discussed prognosis with their patients compared to the Swedish nurses. In contrast, a study evaluating communication about prognosis in terminally ill patients with cancer in seven different countries, including Sweden and the Netherlands, found that Swedish physicians were more likely to discuss prognosis compared to their colleagues in other countries (106).

Discussing these subjects with terminally ill cancer patients might be easier than discussing them with patients with $\mathrm{HF}$, as the course of the illness is more unpredictable compared to cancer patients. It is also possible that Swedish physicians are more likely to discuss prognosis than HF nurses, so Swedish nurses might not feel the need to do so.

Another study investigated end-of-life care decision-making in four European countries (Belgium, Denmark, Sweden, and Switzerland). It was found that there was less patient involvement in end-of-life decisions in Sweden and Denmark compared to the other participating countries. The authors suggested that cultural and country-specific variables probably play a role in these differences (107).

\section{Variables related to communication}

In an additional analysis on the same study sample as used in study II, we found that different variables (patient and nurse-related) had an impact on communication about prognosis in Swedish and Dutch HF clinics (108). Prognosis was more often discussed with patients in a higher NYHA functional class. This could be due to these patients being more symptomatic and having more severe HF. Thus, nurses possibly find it more relevant or feel more comfortable discussing prognosis with patients who are closer to the end-of-life. Furthermore, the nurses with more knowledge on discussing prognosis more often discussed the topic with their patients, although most of the nurses (70\%) reported a need for education about discussing 
prognosis. It seems logical to assume that having more knowledge makes it easier to discuss the topic. However, most of the nurses (70\%) and 67\% of the nurses who discussed prognosis with their patients also reported a need for extra education about discussing prognosis, which may reflect that having knowledge alone is not enough to have a good discussion about prognosis with the patient.

Previous research has reported that nurses who have additional education about discussing sensitive topics, for example, sexual activity, are more comfortable and active in discussing these topics with their patients (81). Hence, nurses in both Sweden and the Netherlands might need more knowledge, confidence and skills to communicate about these sensitive topics with their patients.

\section{A team approach}

Recently collected data on 34 Dutch cardiologists' perspectives on discussing prognosis with HF patients is described in an abstract that will be presented at the Heart Failure Congress 2018 (van der Wal et al. 2018). Most of the cardiologists (95\%) stated that discussions about prognosis should be initiated by the patient's own cardiologist. Still, $72 \%$ also reported that another cardiologist could discuss this with the patient on the ward, in case of a hospitalization, or the nurse at the HF clinic (58\%). Most cardiologists in this survey did not find it very difficult to discuss prognosis with their patients and suggested that it should be discussed when the diagnosis is assessed. Most of the cardiologists reported that the patient's own cardiologist should discuss the prognosis with the patient, although this could also be done by other health care professionals (cardiologist on the ward, HF nurse). A team approach seems important to improve discussing prognosis with HF patients. Both the physician and the nurse (and if appropriate, other health care professionals) should take responsibility for these discussions (109). In the future, data will be collected also on Swedish cardiologists' perspectives on communication about prognosis, as this is an area in need of improvement.

\section{Patients' perceptions of communication about the HF trajectory}

\section{Preferences}

The patients in this thesis described how their previous experiences of conversations about prognosis with a health care professional had an impact 
on their preferences for future conversations. Some patients were ambivalent in their approach towards discussing prognosis. They wanted to know the truth about their prognosis but at the same time they did not want to know anything as they feared they might hear something they did not want to hear. Similar results have been found in another study performed in Sweden (110). In that study, a lack of prognostic information and understanding among HF patients was discovered, with some of the patients expressing that they did not wish to know much about their prognosis, leaving this matter to the physician. Other patients wanted to know more about their prognosis and claimed that is was their right to be informed. It was also revealed that patients had different perceptions of what their prognosis implied. Some of these perceptions were unrealistic and the authors suggested that patient information concerning prognosis should be provided individually and according to the actual patient's capacity, emotional reactions and wishes (110). This approach has also been seen in cancer patients where patients are ambivalent regarding how much information they want about their prognosis. Patients might even become angry when receiving information, even if they asked for it. Professionals who experience these reactions from patients might avoid discussing prognosis in the future (64).

In this thesis it was discovered that patients' knowledge about their illness had an impact on their perspectives of communication about the future (III). When patients understood the seriousness of their illness, they showed a greater interest in discussing the future, often searching for more information about their illness on their own. Heart failure has been described as controlling the patients' lives, however, for those who have accepted their situation, death seems like a natural end to their illness and they do not fear talking about death and dying. Yet, many patients described that professionals provide little or no information about the illness progression, leaving the patients with a limited understanding of their illness. When professionals do not discuss prognosis and the future, patients might not know that they are suffering from a chronic illness. As a result, they seldom reflected about their future living with HF. These patients seemed unrealistic and unaware about what the future might bring. This unreflective thinking was probably caused by professionals' avoidance to discuss prognosis, resulting in a lack of information about the seriousness of $\mathrm{HF}$ as a chronic illness.

More than ten years ago (111), Caldwell et al. (2007) interviewed Canadian HF patients about their preferences for prognosis communication. At that time, there was little evidence to suggest that prognosis was discussed with 
patients based on their preferences concerning the information given or the way the communication process was executed. The patients in that study had a more advanced HF than the patients in study III in this thesis, but the results are quite similar. In our study, it was described that patients had different approaches to communication about prognosis and used different coping styles to handle living with a life-threatening illness such as HF. Similar results were found in Caldwell's study, and the two themes in the two studies have several similarities. It is interesting to compare Caldwell's "Tell the truth" with our study III. "Nothing but the truth", and "Maintain hope" can be compared with the theme "Good news only" in study III. In both studies, some patients expressed that they wanted to know the objective truth about their illness as a way to prepare themselves for the future. Other patients preferred to know the positive truth about the prognosis, to at least maintain hope when they received information about their prognosis. To satisfy these different preferences for communication, Back et al. (2003) have described an approach that might be useful - "Hoping for the best but preparing for the worst" (112). Using this approach, the professionals can be open and honest about the prognosis, and balance the discussion with the assurance that they are working with the patient in trying to prolong life and improve quality of life. This approach is in line with an open awareness context (54), but also strives to make the patient and their family members feel hopeful about the future.

\section{Coping strategies}

Previous research has shown that patients use different strategies to cope with life with a serious illness (113). This can make communication about the HF trajectory difficult. Coping is described as consisting of "cognitive and behavioural efforts to manage specific external and/or internal demands that are appraised as taxing or exceeding the resources of the person" (114). In order to discuss the HF trajectory with patients according to their needs and preferences, health care professionals need to understand that patients might have different ways of coping with the illness and hence use different approaches to discuss this topic. How much information about the HF trajectory the patients wanted varied in this study (III), which has also been found in other studies (111). It is important for health care professionals to realize how patients' understandings of their illness have an impact on their preferences for communication in clinical practice. There is no quick fix for health care professionals who want a good communication about the HF trajectory with patients. Rather, they might need to use proper communication techniques and tailor the information to the 
actual patient. An individual approach is emphasized in the communication as it has been suggested that knowledge about the illness is not always beneficial to all patients, at all times (64). Each patient has a personal experience of their illness, which might or might not be similar to other patients' experiences. Therefore, it is important that health care professionals who meet these patients try to understand what impact HF has on each individual patient and that they adapt the care and communication to each individual (18).

\section{Learning to communicate}

In this thesis, many nurses reported a lack of education and training about discussing prognosis and end-of-life care. They also reported a need for further training (I). A lack of communication skills was reported as a barrier in communication with patients, and one third of the nurses (I) agreed that they did not know how to discuss prognosis or end-of-life care with the patient. Guidelines state the importance of good communication about the HF trajectory, as well as the need for communication training for physicians and nurses working in the field of HF (115).

A literature review (116) examined how education on end-of-life care is provided to undergraduate nurses. It was found that they are not adequately educated, which makes many nurses feel unprepared to deal with issues in connection with death and dying. Simulation was one innovative teaching method that was suggested to help prepare nursing students for providing end-of-life care.

Simulation can be defined as "an event or situation made to resemble clinical practice as closely as possible" (117). A review of the simulation literature (118), supported the assumption that simulation can be a useful teaching method in end-of-life care, but that qualitative research is needed to adequately explore nursing students' experiences of such a teaching method.

The end-of-life care education described in study IV showed that palliative simulation can be a good learning opportunity for nursing students as they are provided with a realistic situation where they can practice handling end-of-life care conversations with patients and family members. This is in line with previous studies in the same field. In a recent systematic review (119), the impact of simulated patients on communication skills in health care was studied. The authors concluded that simulation training is valua- 
ble and effective for teaching communication skills. Simulation training allows the learner to practice in a realistic environment and receive feedback on their behaviour.

In another study, Back et al. (2007) designed and evaluated a communication skills workshop (Oncotalk) for physicians. The training was organized around simulated patients with cancer. They study demonstrated improved communication skills among the participants. They gained new skills along with a behaviour change that had an impact on patient-centeredness (120).

Research evaluating simulation training is mostly based on samples including students. However, it seems reasonable to believe that simulation training has the potential to be useful also for clinicians who have already been working for some time in clinical practice. Linköping University has a clinical skills and simulation centre for the health professional education, where both students and clinicians are welcome to practice. The teachers at the skills and simulation centre use problem-based learning. This is based on the idea that the best situation for an adult to learn is when he/she sees a problem that needs to be solved in real life (99). Health care professionals working in HF care could benefit from such simulation training, as it could prepare them for discussing the HF trajectory and end-of-life care with patient and families.

\section{Improving communication}

In this thesis, an intervention was developed based on the ideas from the ideas groups previous literature from both cancer care and heart failure care, and simulation education. Further in, some areas of feasibility of the intervention was tested. Patients, family members, and health care professionals were all important contributors in the development of the intervention. In the co-design process, the participants shared their experiences of communication about the HF trajectory and expressed what they needed in order to enhance such communication.

\section{A dual component intervention}

The QPL described in this thesis supports patient-centred communication (6) helping the patient to focus the conversation on the topics that are most relevant to them. Patient-centred communication is further emphasized in the learning goals of the communication course, where it was stated that communication with the patient/family should be individualized and based on their needs and wishes. 
Providing a QPL in clinical practice can increase the amount of question a patient asks if the QPL is endorsed by the clinicians and tailored to the patient (121-123). However, providing a QPL for the patient and their family, thereby helping them to initiate a conversation, might not be enough to improve communication. Health care professionals also need to be prepared to discuss the patient's and family members' questions (124). It is known that many professionals want more education and training on how to discuss prognosis and end-of-life care (I+II). Therefore, it was an important step in study $\mathrm{V}$ to also add a communication course to support the health care professionals and make them feel knowledgeable, skilled and confident to discuss the topics in the QPL.

\section{The Question Prompt List}

Previous research on QPLs are mostly from cancer care. In an RCT study, Clayton et al. (2007) showed that a QPL that was endorsed by a physician helped cancer patients and their family members ask questions about prognosis and end-of-life care without causing patient anxiety (125). In another RCT study, Walczak et al. showed that a nurse-led communication support program including a QPL helped cancer patients and their families to give cues that they wished to discuss prognosis and end-of-life care (126).

Walczak et al. (2015) have explored cancer patients' and their family members' responses to a nurse-facilitated delivery of a QPL, focusing on end-oflife issues (127). The patients had a life expectancy of less than one year. The response to the QPL was generally positive, with approximately $55 \%$ of the patients stating that they would use the QPL in the future. In some participants, however, the QPL raised negative emotions. Patients and family members who wanted a lot of information and who seemed more involved in the care, as well as those who seemed to discuss end-of-life care issues responded most positively to the QPL.

To our knowledge, the QPL described in this thesis is the first one developed and evaluated in an HF care context. A study from 2001 (128) described the use of a checklist with questions to improve patient education in cardiology. Some years later, Bolman et al. (2005) evaluated the longterm efficacy of the same checklist. It was concluded that the checklist could be a useful tool for preparing the patient for the visit to the cardiologist (129). Our QPL showed similar results, but it is different as it is supposed to be used in discussions between patients, their families and several cardiac professionals, not only by a cardiologist in a doctor-patient communication. In addition, our QPL focused specifically on questions around 
about the HF trajectory, whereas the Dutch checklist had a more general approach with questions about the cardiac disease.

A prognosis-focused QPL can be one way to improve patients' and families' prognostic awareness (130), however, using a QPL in clinical practice might also be a challenge. Health care professionals who find it difficult to talk about the issues may find the list distressing. On the other hand, the QPL might be a way to legitimize these sensitive questions and help build relationships between patients, family and health care professionals. Thus, both patients and family members can be empowered.

The characteristics of the QPL (for example, the provider training and the number of questions) can influence the effectiveness of the QPL (122). It is important to further test the QPL developed in this thesis in clinical practice in order to determine the optimal formulation and number of questions, and at what time point the QPL should be provided to patients and families.

\section{The communication course}

The course that was developed and tested in this thesis addresses the issue of communication with patients and family members about the HF trajectory, using an approach that is individualized to the situation and meets the needs of the patient and the family. The course aims at giving the participants knowledge about the importance of discussing the HF trajectory with the patient and the family. They are given a chance to practice discussing the HF trajectory with simulated patients and family members using the QPL.

It seems important to provide training for professionals to enhance their ability to communicate with patients and their families regarding these topics. Communication tools is one way that could that help them to initiate these conversations earlier in the illness trajectory (131).

\section{Patient-professional communication in health care}

Feldman-Stewart et al. have described a conceptual framework for patientprofessional communication that can occur between a health care professional and a patient (132). This framework is based on both the process- , and the semiotic school of communication described by Fiske (3). The framework consists of four key components that impact a patient-professional communication: the environment, the participants, the interaction, and the communication process. The framework focuses on a one-to-one 
communication between the patient-professional dyad, but also has the potential to include a more individual application of the principles of the framework to all individuals involved in the communication process (132).

Feldman-Stewart et al. (2005) have suggested that each communication process in health care takes place in a complex environment with external social, cultural, legal and physical factors. The communication process is also a direct function of both participants' key attributes, such as needs, beliefs, values, skills, and emotions. These attributes affect the form and the content of the messages he/she conveys.

The environment for the communication process described and discussed in study I-III and V, is the HF clinic where the patient and the family member visit a nurse or a physician to discuss possible HF symptoms, check the patient's blood pressure and perhaps adjust the dose of medication.

The patients enter the communication process with their own attributes that impact the communication (132). Some patients might lack information from health care professionals about the possible HF trajectory as described in study III, where the communication mostly focused on the treatment and management of $\mathrm{HF}$.

As described in study I-II, the nurses at the clinic can be uncertain about how to initiate a discussion about the HF trajectory with patients and family members. They might wait for the patient or the family members to ask questions, but if the patient is deteriorating or has previously been hospitalized they sometimes regard these circumstances as reasons to initiate a discussion of the patients' preferences for future care.

This thesis shows that if a patient asks questions, the HF nurses regards this as a facilitator for communication, showing them the patient's preferences and needs in terms of a communication (II). A QPL might help the patient and the family members to ask questions and facilitate the communication process for the health care professional. However, as the QPL has not been tested in patients and family members, further studies are needed to explore the feasibility of the QPL in HF patients and their families.

The communication course including simulation training might also function as a facilitator for communication as it seems to have the potential to improve professionals' knowledge, confidence and skills to discuss the HF trajectory with patients and their families. Hence, it can be advocated that the intervention in this thesis, including a QPL and a communication course, might facilitate a successful communication between a patient, a family member and a health care professional in HF care. 


\section{Patient-centred communication}

In the communication with the patient and the family within the HF care context, the health care professional could be inspired by two concepts; person-centred care (104) and patient-centred communication (105).

According to Ekman et al. (2011): "a person-centred approach to care can explain and predict individual exception based on who the person is: their context, their history, their family and loved ones, their individual strengths and weaknesses". This means that health care professionals should have both an objective understanding of the illness (which can be described with through anamnesis and examinations), but also a subjective understanding of the patient's experiences and perceptions of their illness (104).

In the communication, it is important for the professionals to listen to the patient's narratives, as this is an important step in building a good partnership, thereby facilitating a person-centred care (104). If there is a good partnership between the patient and professionals, the foundation is laid for the patient to participate in the decision-making of the care. In addition, it is crucial that the professionals document what has been discussed and decided about the care in the patient's records.

In cancer care research, the concept patient-centred communication has been described by Epstien and Street (2007) as communication that must help patients to handle the emotional impact of a life-threatening illness, receive bad news and make decisions about treatment (6).

In the communication with a patient in a HF care context, it is important to strive for a patient-centred communication where the patient maintains his/her level of autonomy (133). The patient and family members need to understand the unpredictability of the HF trajectory in order to be involved in the care, make choices, plan for the future and prepare for end-of-life $(13,134)$. When planning for a discussion about the HF trajectory, the algorithm described by Jaarsma and Strömberg (2016) could be useful. The algorithm can help health care professionals evaluate and re-evaluate the focus and goals of care throughout the whole HF trajectory (39).

\section{Methodological considerations}

The studies in this thesis includes methods suited in both the positivistic and the naturalistic paradigm (135), using questionnaires and/or interviews and/or observations to answer the research questions. This means that the participants' reality has been both objectively measured (as far as 
possible), but the research has also produced data that are the result of interactions between the researcher(s) and the participants.

\section{Internal and external validity}

\section{Sample}

In this thesis, different samples were used, including health care professionals, patients and students.

The health care professionals were mostly female HF nurses with a mean of $12 \pm 8$ years of professional experience and can be considered to be a representative sample of HF nurses in Sweden and the Netherlands.

The aim was to include all nurses working in HF clinics in Sweden and the Netherlands and power calculations to determine the number of nurses needed to answer the research question were not done.

In study I-II and V in this thesis, a nationwide invitation was sent out to cardiac health care professionals, inviting them to participate in the studies. However, there might have been a selection bias as only the most motivated professionals who were interested in the aim of the studies participated. At the same time, many professionals were surprised about the aim of the studies, i.e. describing the practice of discussing prognosis and endof-life care in HF clinics, as they thought that the aim was to collect data in the wrong context. Many commented that the patients in HF clinics are too stable to have such conversations. Yet, even if some of the nurses were somewhat uncertain that they were the most suitable participants for in the study, very few declined to participate. However, it needs to be recognized that the results might have been different if the data had been collected in a more palliative care setting than the HF clinic.

The fact that only one physician was involved in the development of the intervention in study $\mathrm{V}$, and only three were involved in the testing of the intervention (and none of them completed all parts of the course), can also be seen as limitation of the generalizability (78) of the intervention to nonnurse professionals. Preferably, physicians from both general care and cardiology should have participated in all parts of the study in order for it to be more effective and strengthen the external validity (136) of the results. It is suggested from cancer care that QPLs are the most effective when endorsed by a physician, as reported in a randomized controlled trial of a QPL to help advanced cancer patients and their caregivers to ask questions about prognosis and end-of-life care (125). Physicians are supposed to be future users of the QPL and the communication course developed in this 
thesis, and it can be argued that this study is limited by having so few physicians participating. Future steps are to include different health care professionals in further testing of the intervention.

The patients and family members who participated in the interviews and workshop were recruited from two regions in Sweden (Östergötland and Småland). This was due to practical reasons, such as researchers having access to patients in these regions. In addition, the patients and the researcher did not have to travel too far to the interviews and the workshops. There are no obvious reasons why patients in these parts of Sweden would be different from other parts of the country. However, the majority of the patients in the studies were stable HF patients and born in Sweden or similar cultural backgrounds, which limits the generalizability of the results to more severely ill patients, and those born outside of Sweden.

The context of this thesis is the primary health care, where participating health care professionals, patients and family members were recruited. This is an important factor to consider when discussing the external validity (136) of the results. Data was collected from health care professionals who work with stable HF patients and their family members. The results in this thesis can be translated to similar contexts in Sweden and the Netherlands. However, the prevalence and practice of discussing the HF trajectory may be different in other countries and cultures.

The intervention, including a QPL and a communication course, was developed in collaboration with the future users in both palliative and HF care. However, to test the external validity of the intervention, further studies using bigger samples are needed.

\section{Questionnaires}

Some of the questionnaires used to collect data were developed by the research group as no suitable questionnaires were available. Although face and content validity were tested in these questionnaires, there can be limitations in the validity and reliability, and interpretations of the results should therefore be done with caution.

The questionnaire that described nurses' attitudes was based on a previous questionnaire that was developed to describe cardiac nurses' practice, responsibility and confidence in the sexual counselling of cardiac patients (81). That questionnaire had been adapted from the nurses' survey of sexual counselling of MI patients, where a reliability between $0.75^{-0.89}$ had been reported on the different subscales in the questionnaire, using Cronbach's alpha (137). Both questionnaires were found to be suitable to 
for asking nurses about sensitive topics and our adapted questionnaire also worked well for collecting data. The response rate was high (82\%), which might be an indication that the nurses thought that the questionnaire was easy and important to fill in and relevant to their daily work, although, this was not measured (I).

Another questionnaire that was developed by the research group was the registration form that was used to collect data on the prevalence and practice of prognosis and end-of-life care discussions in clinical practice in Sweden and the Netherlands. This registration form might also have validity limitations, as only a basic content and face validity was tested, through discussions in the research group and think-aloud interviews. In the registration form, the participants were asked regarding their communication about prognosis and end-of-life care in HF practice. Although a definition of what "prognosis" and "end-of-life care" implies in these questionnaires, nurses might have their own opinion about the definitions. Therefore, it remains unclear in what way prognosis and end-of-life care actually was discussed during the visits, which is a threat to the internal validity of the questionnaire. In addition, the data was self-reported and there is no way to know what conversation about prognosis and end-of-life care actually took place during the HF clinic visits. It would have strengthened the results if the data collection also had included observational data for triangulation and validation of the results.

The questionnaire that was used to evaluate the limited efficacy of improved knowledge, confidence and skills to discuss the HF trajectory was also developed by the research group, and basic validity and reliability was tested. First, face validity of the questionnaire was tested. The research group discussed what items from the QPL they thought would mirror the learning goals of the course and then included the chosen items in the questionnaire. Second, a 2-week test-retest reliability of the questionnaire was assessed in a group $(\mathrm{N}=13)$ of cardiac health professionals. The test-retest reported the kappa values of the 50 items in the questionnaire. Thirty-four items had a good to moderate agreement, 0.41-0.80, and 16 items had a fair agreement 0.20-0.40 (122). Even if the questionnaire seemed suitable for the study and was the best available option, there is a risk that the validity of the questionnaire is limited, and too strong conclusions of the questionnaire's ability to measure efficacy should not be drawn. 


\section{Trustworthiness}

Lincoln and Guba (1985) suggest the term trustworthiness when evaluating the worth of research performed within the naturalistic paradigm. Trustworthiness involves establishing: credibility, transferability, dependability and confirmability (135).

\section{Credibility}

This concept refers to the amount of "truth" that are in the findings, how confident the reader can be in that the findings are "true"(135).

Integrating focus group and individual interview data (III) can be seen as a method triangulation where the triangulation can achieve a better understanding of the studied phenomena (138). To collect data in this thesis, on different perspectives regarding communication about the HF trajectory, it was important to gain a deeper insight into who the patient felt should talk about the HF trajectory, how they wanted to talk about it, what they wanted to talk about and when. In order to obtain this information, it was suitable to collect qualitative data. Focus group interviews seemed like a useful method. This method allows data to be produced by a group of participants who are discussing a topic of interest to the researcher (84). The method takes advantage of the dynamics in the group, making it possible to gain this information as the participants interact and respond to each other's experiences and perspectives, producing rich information $(78,85)$. Some participants might need to hear others talk about a topic and be inspired in order to talk themselves. In addition, in a focus group it would also be possible to obtain direct reactions and comparisons of differences and similarities from the participants (83). The participants might also feel comforted by being in a group, hearing others' perspectives and learning from each other. However, after performing four focus group interviews and the first initial reading of the collected data, it was concluded that the data might not be rich enough to answer the aim of the study. It was possible that the topic of the discussions in the group was too sensitive for some patients, making the conversations superficial. It might also be a disadvantage to use focus group interviews as the method for data collection in this study, as it explored rather sensitive and difficult topics such as death and dying. These issues could have been discussed further in the research group before deciding on the method, but at that time, the focus group methods seemed most suitable and time-saving. As an alternative data collection method, individual interviews were seen as a complement to the focus group inter- 
views. In such a situation, some participants might feel safer and more confident to open up and freely discuss the topics of the interview. Inspiration to combine two different data collection methods was taken from a study from 2011 by Walczak et al. (139), where they explored cancer patients' perspectives on communication about prognosis and end-of-life care and carried out both focus group-, and individual interviews, collecting useful data for the aim.

However, it is important to consider that the focus group interview and the individual interview are methods that not yield that same kind of data, rather they complement each other (140). With these additional individual interviews the data got much richer and in the end the data from the focus group interviews and the individual interviews complemented each other and the credibility of the findings were improved, using different data collection methods as a triangulation (135).

In the ethnographic study (IV) triangulation was used (78) to compare data that was derived from different locations of the fieldwork. Different data collection methods were used to enable higher confidence in conclusions, including participant- and non- participant observations, video recordings, audio recordings and field notes. One researcher made one participant observation in the field, listen to all audio recordings while making field notes and did the initial analysis of the results. Another researcher looked at all video recordings and made field notes that were merged with the field notes from the other researcher. The two researchers discussed then the findings together before inviting the rest of the co-authors to comment on the final analysis.

Ethnographic research may be a useful method for understanding the student 's experiences when being educated in problem-based learning programs, as the method tries to capture the students' way of life and their culture (141). The data collection is often accomplished through shared experiences and social interaction, where the researcher is active in the field of interest (142). Using the method, both tacit and explicit cultural knowledge can be observed and explored (90). In this thesis, the data collection consisted of mostly non-participating observations with no social interaction between the researchers and the individuals in the field. It is possible that more interesting and rich data could have been obtained, if participating observations had been performed in the simulation and if the students had been interviewed. The ethnographic method provided rich data but in this small-scale ethnographic study the full potential of the method might not have been utilized. However, nowadays it is quite com- 
mon for healthcare researchers to spend less time making participant observations in the field and instead perform small-scale studies with a clear research question in mind from the beginning (143).

\section{Transferability}

This concept shows how applicable the findings are in other contexts (135).

The studies analysing qualitative data in this thesis (I-IV) included both male and female participants in different ages who described various experiences of communication on prognosis and end-of-life care, and together they produced rich data. In the qualitative analyses, we tried to provide rich descriptions of the participants and the context of the study, making it possible for the reader to transfer and apply the results into other fields (135, 144). Even though we had tried to include patients in study III who had much experience and were talkative and willing to share their stories with us, the depth and quality in the information varied. Some participants had little or no experience of discussing the HF trajectory with a health care professional and therefore had little to say about this. Another qualitative methodology could have been used where the scientific framework suggest that participants should have an experience of a certain phenomenon, for example phenomenography (145). Others had difficulties to share their experiences in the focus group, or individual interview, or where more interested in the social event the focus group or the individual interview produced.

It can be assumed that the results from this thesis can be applied to HF patients in Sweden and the Netherlands and nursing students in Sweden. However, the students were recruited from a nursing program in one university where they had been using PBL and simulation throughout their whole education. Hence, these students were used to the self-directed learning methods and the simulation procedure, and students from other universities in Sweden and other countries, using different teaching methods, could possibly find the simulation training more challenging and difficult then the students in our study.

\section{Dependability}

This concept shows that the findings are consistent and stable over time and conditions (135).

A semi-structured interview guide (86) was used in study III to make sure the participants received the same questions and to simplify comparison between the interviews. The analysis of qualitative data in this thesis was 
performed systematically following established methods. Qualitative content analysis $(93,94)$ was used in study I-II, a method that aims to interpret the content of text data, using a systematic classification process with coding and identifying patterns and themes. Qualitative content analysis comprises descriptions of both manifest content that is close to the text, and latent content that is an interpretation of what is between the lines (94, 146). Both approaches of analysing data were used in study I-II as some text was short including only some words, and other data was more detailed with several sentences, allowing more interpretations. The amount of data was huge in the studies where responses from 111 nurses were included in study I and responses from 279 nurses were included in study II. With so much data it was a challenge to get a good overview of the data in the analysis and using a qualitative content analysis could be seen as a disadvantage in these studies. It was discussed in the research group if quantitative content analysis should have been used instead, but that would also limit the possibility of interpretations in data.

Braun and Clarke's version of thematic analysis was used in study III, as a flexible method was needed that could analyse data from both individual, and focus group interviews $(95,96)$. For us, the thematic analysis allowed more depth and interpretations in the analysis as the unit of analysis tend to be more than a word or phrase, which a qualitative content analysis often is more concentrated on (96).

In study $\mathrm{V}$, data from the idea groups (field notes and audio recordings) and data from the open-ended questions in the questionnaires was evaluated, discussed and summarized in the research group. As the aim was to identify improvement ideas expressed by the participants, and evaluate the intervention, the data was summarized without an in-depth qualitative analysis. However, this lack of a standardized analysis of the qualitative data might limit the dependability of the results. On the other hand, performing a qualitative analysis of data that was collected to be used as a course evaluation could possibly have produced findings with little depth and quality.

In the analysis of the qualitative data in study III in this thesis, there was no defined framework that had been used beforehand. However, it can be argued that a critical realist framework (147) was applied in the analysis. In this framework, socially produced meanings are discussed while these also are understood to have some kind of relationship to an experiential reality for people. This means that in the data analysis, the participants' responses were treated as being real for them but considered as products of socially available meanings. 
To assess the stability of data over time and conditions, our data was compared with other studies with the same research questions (78). In study III similar findings were found in, for example, Caldwell's study (111), and the results in study IV were comparable with existing literature within the end-of-life care education $(118,148)$. These similarities with other studies could possibly also mean that our studies are a repetition of previous research, describing no new knowledge. However, there were also new results found in our data that have not, to our knowledge, been described before. The results in this thesis confirm previous research but also add new knowledge, such as the importance of the patient's previous experiences of communication about the HF trajectory and how these experiences affected how they wanted to communicate with professionals in the future. The results also had an impact on the way the patients coped with their lifelimiting illness.

\section{Confirmability}

This concept refers to the extent the findings are shaped by the participants and not by the researcher's interest and bias (135).

It is important to discuss to what extent the data and interpretations of the studies are grounded in actual events rather than the researcher's personal constructions (135). Researcher triangulation was one way to make sure that the interpretations of the data were grounded in the data, thus making it clear that all authors agreed on the results and that they could easily identify the suggested results in the raw data. On the other hand, using researcher triangulation, where only the data that is agreed upon, makes it to the final results, can cause interesting data to be lost in the process. The risk that this was the case in the studies in this thesis (I-IV) is believed to be little as there were several researchers taking part in the analysis process, also looking and analysing the raw data.

The individuals in the research group have different pre-understandings and experiences from $\mathrm{HF}$ and palliative care, which can influence the data analysis. However, it is important to consider that in the naturalistic paradigm, the reality is not fixed, but it is a construction made by the partici-

pants in the research. Many different constructions are possible and reality exists surrounded by a context $(78,135)$. The results in the studies are the reality that was created between the researchers and the participants in the studies, and we used our pre-understandings as important tools to understand and analyse the data. 


\section{Clinical implications}

- Discussions about the HF trajectory should be included as a part of the daily routine at HF clinics in Sweden and the Netherlands.

- Heart failure nurses should be encouraged to take more responsibility for discussing the HF trajectory with patients and their families.

- Clinical policies for these discussions should be developed in each HF team.

- Discussions should always be tailored to each individual patient's needs, wishes and preferences.

- Simulation training is one way for students and clinicians to practice and learn good communication skills in end-of-life care conversations.

- A QPL can help patients and family members to initiate discussions about the HF trajectory.

- A communication course can help professionals gain the knowledge, confidence and skills required to discuss the questions raised by patients and their families. 


\section{Future research}

This thesis focuses mostly on the nurses' and the patients' perceptions of communication about the HF trajectory. However, in the future it is important to also describe the views of other relevant health care professionals working with these patients. The family members' perspectives also need to be further described to understand their needs and preferences for communication.

Future interventions aiming to improve communication about the HF trajectory need to consider international differences that might exist in theses communication situations, both in relation to the patient, the family members and the health care professionals.

Future research needs to evaluate the impact of providing the QPL to patients and family members at different time points in the HF trajectory, patients and family members might want different amounts of information during the illness trajectory. 


\section{CONCLUSIONS}

This thesis shows that prognosis and end-of-life care are seldom discussed with HF patients in Swedish and Dutch HF care. In addition, many HF nurses have ambiguous attitudes towards discussing these topics with patients and their families. It can be argued that in both Sweden and the Netherlands, the prevalence and quality of communication need to be improved. There are several barriers, as well as facilitators that can impact such communication. The nurses expressed a need for more education and training to discuss the prognosis and end-of-life care with patients and their families.

Patients have described that they receive different kinds of messages concerning their HF. They also have different preferences for discussing the HF trajectory with health care professionals. Most patients want the health care professionals to be honest about the future and help the patient to be prepared. When health care professionals act as if ignorance is bliss, keeping important information from the patient, they can deprive the patient from being able to plan ahead and be prepared for a time when their HF is deteriorating. At the same time, some patients prefer to ignore the fact that they might die from their HF and want to live one day at the time. Other patients want a little more information, but only the good information, about their prognosis. Therefore, is important that the health care professionals who discuss these topics with patients try to understand what impact HF has on each individual patient and family member and adapt the communication accordingly.

End-of-life care simulations has shown great promise for health care professionals to practice end-of-life care conversations. It is important that there are skilled supervisors present who can guide the learning process and make sure that they learning focuses also on existential dimensions, including psychosocial aspects of the communication.

Patients, their families and health care professionals were interested and engaged co-designers in the development process of the intervention aiming to improve communication about the HF trajectory. A QPL and a communication course were developed and tested. As the feasibility testing showed promising results, the intervention might be useful for improving communication about the HF trajectory in patients, their families and health care professionals. Using co-design as a method for developing the 
intervention is in line with a palliative care philosophy focusing on the actual needs and wishes of patients and their families. 


\section{SVENSK SAMMANFATTNING}

Introduktion: Den senaste tiden har det blivit en ökad medvetenhet inom kardiolgi vad gäller nödvändigheten att kunna erbjuda palliativ vård till patienter med hjärtsvikt. Kliniska riktlinjer påpekar vikten av att diskutera hjärtviktens sjukdomsförlopp med patienter och deras familjer. Dessa diskussioner kan innehålla att prata om prognos, förväntningar inför framtiden och vård $\mathrm{i}$ livets slutskede. För vårdpersonal inom hjärtsviktsvården verkar det ofta vara svårt att initiera dessa samtal och de undviker att prata om dessa områden då de är rädda att ta bort hoppet för framtiden och orsaka oro hos patienter och deras familjer.

Syfte: Det övergripande syftet med denna avhandling var att förbättra kommunikation om hjärtsviktens sjukdomsförlopp hos patienter, deras familjer och vårdpersonal.

Design och metod: Denna avhandling innehåller 5 studier med olika design och datainsamlingsmetoder. Studie I var en tvärsnittsstudie där frågeformulär användes för att samla in data för att beskriva hjärtsviktssjuksköterskors uppfattningar och kliniska arbete när det gäller att diskutera prognos och livets slutskede med patienter. Studie II hade en deskriptiv och jämförande design där en enkätundersökning genomfördes för att beskriva svenska och nederländska hjärsviktssjuksköterskors skäl för att diskutera eller inte diskutera prognos och livets slutskede med patienter. Studie III hade en induktiv och explorativ design där hjärtsviktspatienter deltog i fokusgruppsintervjuer och individuella intervjuer och data samlades in för att beskriva deras uppfattningar om kommunikation om hjärtsviktens prognos. Studie IV var en mindre etnografisk studie som beskriver och utvärderar simuleringsträning för sjuksköterskestudenter under deras sista termin på programmet. Studie V använde co-design och bjöd in patienter med hjärtsvikt, deras familjemedlemmar och vårdpersonal (läkare och sjuksköterskor) från palliativ vård och hjärtsviktsvård, för att delta i designprocessen där man skulle arbeta fram en intervention som syftade till att förbättra kommunikation om hjärtsviktens sjukdomsförlopp. Sjuksköterskor deltog sedan i en testning av interventionen.

Resultat: De flesta hjärtsviktssjuksköterskor hade diskuterat prognos (96\%) och livets slutskede (84\%) med en hjärtsviktspatient vid något tillfälle i sitt kliniska arbete. Sjuksköterskorna ansåg att en läkare oftast borde vara huvudansvarig för dessa diskussioner (69\%) men ansåg också att sjuksköterskor kunde ha en roll i dessa samtal (I). Prognos och livets slutskede 
var, (tillsammans med sexualitet) de tre minst förekommande ämnena som diskuterades på hjärtsviktsmottagningar i både Sverige och Nederländerna (II). I de 1809 patientsamtal som samlades in bland svenska och nederländska patienter, diskuterades prognos med $38 \%$ och livets slutskede diskuterades med $10 \%$ av patienterna. I studie III uttryckte patienterna olika erfarenheter och preferenser vad gäller att prata om hjärtsviktens prognos. Många patienter beskrev att vårdpersonal inte hade gett dem någon information överhuvudtaget om prognos. Patienterna hade olika förståelse för hjärtsvikt som ett kroniskt tillstånd vilket också påverkade vilka preferenser de hade kring att samtala om prognos (III). Simuleringsträningen som beskrevs i den etnografiska studien (IV) var en del av en simuleringsträning som sjuksköterskestudenter deltog i för att lära sig mer om palliativ vård och vård i livets slutskede. Studenterna uttryckte att simuleringsträningen var ett bra lärtillfälle för att kunna handskas med vård i livets slutskede och också gav dem chansen att reflektera över sina egna tankar och känslor inför död och döende. I studie V utvecklades en intervention som bestod av ett samtalsstöd för patienter och deras familjer samt en kommunikationskurs för vårdpersonal.

Konklusion: Denna avhandling visar att prognos och vård i livets slutskede sällan diskuteras med hjärtsviktspatienter i svensk och nederländsk hjärtsviktsvård och att många sjuksköterskor har ambivalenta attityder till att diskutera dessa områden med patienter (I+II). Patienter med hjärtsvikt har beskrivit att de fătt olika besked om sin hjärtsvikts prognos och att de också har olika preferenser för att diskutera detta. Patienterna vill att vårdpersonal försöker förstå vilken påverkan hjärtsvikten har på varje patient och anpassar kommunikationen för varje individuell patient (III). Simuleringsträning inom palliativ vård där erfarna och skickliga handledare deltar i undervisningen, kan erbjuda ett bra träningstillfälle för sjuksköterskestudenter, och utexaminerad vårdpersonal, att träna på att få till det goda samtalet med patienter och närstående i livets slutskede. Ett samtalsstöd och en kommunikationskurs kan vara användbart för att förbättra kommunikation om hjärtsviktens sjukdomsförlopp med patienter, deras närstående och vårdpersonal.

Nyckelord: Hjärtsvikt, sjuksköterskans attityder, prognos, vård i livets slutskede, kommunikation, palliativ vård, utbildning i livets slutskede, simulering, sjuksköterskestudenter, co-design 


\section{ACKNOWLEDGEMENTS}

I want to express my warmest gratitude to those who have supported me in the work with this thesis.

First of all, thank you to all the participants in the studies. Without you there would not be any thesis to write.

Professor Tiny Jaarsma, my main supervisor. Thank you for being a great supervisor, sharing your vast experience of research and guiding me through my $\mathrm{PhD}$ time. You know me very well and have always supported me in a way that I needed at each specific time. I have appreciated that I always could share both my professional life and my personal life with you and you have inspired me both as a researcher and as a person. Thank you also for being a good friend during these years. I am very grateful that you believed in me and wanted me to be one of "your" PhD students.

Professor Anna Strömberg, my co-supervisor. You have been a big inspiration for me and I admire how skilled you are in so many different areas in research, but also in private life. Thank you for all the help, support and guidance you have provided me during these years.

Associate professor, Maria Friedrichsen, my co-supervisor. Thank you for all that you have shared of your great experience and knowledge of palliative care and qualitative research. Your research of have been an inspiration for me in my studies. Thank you for your guidance in interviewing patients about sensitive topics, I have learnt so much from you.

Professor Jan Mårtensson, my co-supervisor. Thank you for being an encouraging and supportive supervisor, always providing thoughtful comments and suggestions to help me improve my research.

Dr Martje van der Wal, colleague and co-author. Thank you for being like an extra supervisor to me during these years, always supporting me with patience and humour. Thank you for the great collaboration we have had, and are continuing with, in our joint research projects in Sweden and the Netherlands. I look forward to continue working with you.

Associate professor, Anna Sandgren, colleague and co-author. I want to thank you for a great collaboration in our joint projects. You have shared your experiences and knowledge of palliative care and qualitative research and it has been a pleasure to work with you.

Associate professor, Anna Milberg, colleague and co-author. Thank you for being such positive person to work with. Your enthusiasm and hard 
work have been an inspiration for me and I look forward to future join research projects.

Dr Anita Kärner Köhler, colleague and co-author. Thank you for being a supportive researcher and friend. You were the one who invited me to my first conference and let me "taste" the research life, doing my master thesis as a part of your research project COR-PRIM. I will always be thankful to you for that, it was an important step in my career. Hopefully we will find new research projects to work with together in the future.

I also want to express my gratitude to Katarina Karlsson and Louise Olsson for your support and collaboration in the simulation research.

Thank you to doctoral colleagues, post docs and staff at the Department of Social and Welfare studies and at the Department of Medical and Health Sciences for help and support during these years. Many of you have become dear friends to me, and we have shared a lot.

A special thanks to my dear colleague and friend Dr Leonie Klompstra. We have shared so many things during these years and it has always been an adventure to do research, or going on conferences with you.

Thank you to my family and friends for your love and support. You are all very important to me and I am so grateful that I have you in my life.

An extra thanks to my dear friend JoAnna S Fransson for making the lovely picture at the front cover of the thesis.

Finally, I want to show my deepest appreciation to Simon Hjelmfors, my dear husband for all your love and support during my PhD time. Thank you for sharing this research journey with me. Without you, the journey would have been much more difficult and less fun. 


\section{REFERENCES}

1. Dias L, Chabner BA, Lynch TJ, Penson RT. Breaking bad news: a patient's perspective. The Oncologist. 2003;8(6):587-96.

2. Northouse LL, Northouse PG. Health Communication Strategies for Health Professionals: APPLETON \& LANGE; 1998.

3. Fiske J. Introduction to communication studies: Routledge; 2010.

4. Stewart MA. Effective physician-patient communication and health outcomes: a review. CMAJ: Canadian Medical Association Journal. 1995;152(9):1423.

5. Silverman J, Kurtz SM, Draper J. Skills for communicating with patients: London : Radcliffe, cop. 2013 3. ed.; 2013.

6. Epstein R, Street RL. Patient-centered communication in cancer care: promoting healing and reducing suffering: National Cancer Institute, US Department of Health and Human Services, National Institutes of Health Bethesda, MD; 2007.

7. Gysels M, Richardson A, Higginson IJ. Communication training for health professionals who care for patients with cancer: a systematic review of effectiveness. Support Care Cancer. 2004;12(10):692-700.

8. World Health Organization (WHO). WHO definition of palliative care. Available from www.who.int/cancer/palliative/defini ion/en/ Accessed 2 January 2014.

9. The Swedish National Board of Health and Welfare. National Guidelines for Cardiac care. 2015. Available from http://www.socialstyrelsen.se/publikationer2015/2015-10-4. Last assesed 2018-03-22.

10. Dying in America: Improving Quality and Honoring Individual Preferences Near the End of Life 2015. Available from https://www.nap.edu/read/18748/chapter/1 Last assessed 2018-03-22.

11. Doyle D, Hanks GWC, MacDonald N. Oxford textbook of palliative medicine (2nd ed.). New York, NY, US: Oxford University Press; 1998.

12. Lindqvist O, Tishelman C, Hagelin CL, Clark JB, Daud ML, Dickman A, et al. Complexity in non-pharmacological caregiving activities at the end of life: an international qualitative study. PLoS medicine. 2012;9(2):e1001173. 
13. Zarrinkoub R, Wettermark B, Wändell P, Mejhert M, Szulkin R, Ljunggren $\mathrm{G}$, et al. The epidemiology of heart failure, based on data for 2.1 million inhabitants in Sweden. Eur J Heart Fail. 2013;15(9):995-1002.

14. Mosterd A, Hoes AW. Clinical epidemiology of heart failure. Heart. 2007;93(9):1137-46.

15. Jaarsma T, Beattie JM, Ryder M, Rutten FH, McDonagh T, Mohacsi P, et al. Palliative care in heart failure: a position statement from the palliative care workshop of the Heart Failure Association of the European Society of Cardiology. Eur J Heart Fail. 2009;11(5):433-43.

16. Goodlin SJ. Palliative care in congestive heart failure. J Am Coll Cardiol. 2009;54(5):386-96.

17. Dickstein K, Cohen-Solal A, Filippatos G, McMurray JJ, Ponikowski P, Poole-Wilson PA, et al. ESC guidelines for the diagnosis and treatment of acute and chronic heart failure 2008: the Task Force for the diagnosis and treatment of acute and chronic heart failure 2008 of the European Society of Cardiology. Developed in collaboration with the Heart Failure Association of the ESC (HFA) and endorsed by the European Society of Intensive Care Medicine (ESICM). Eur J Heart Fail. 2008;10(10):933-89.

18. Olano-Lizarraga M, Oroviogoicoechea C, Errasti-Ibarrondo B, SaracíbarRazquin M. The personal experience of living with chronic heart failure: a qualitative meta-synthesis of the literature. Journal of clinical nursing. 2016;25(17-18):2413-29.

19. Mamas MA, Sperrin M, Watson MC, Coutts A, Wilde K, Burton C, et al. Do patients have worse outcomes in heart failure than in cancer? A primary care-based cohort study with 10-year follow-up in Scotland. European Journal of Heart Failure. 2017.

20. Ørn S, Dickstein K. How do heart failure patients die? European Heart Journal Supplements. 2002;4(suppl_D):D59-D65.

21. Goodlin SJ, Quill TE, Arnold RM. Communication and decision-making about prognosis in heart failure care. J Card Fail. 2008;14(2):106-13.

22. Ponikowski P, Voors AA, Anker SD, Bueno H, Cleland JG, Coats AJ, et al. 2016 ESC Guidelines for the diagnosis and treatment of acute and chronic heart failure: The Task Force for the diagnosis and treatment of acute and chronic heart failure of the European Society of Cardiology (ESC) Developed with the special contribution of the Heart Failure Association (HFA) of the ESC. European heart journal. 2016;37(27):2129-200.

23. Epstein AE, Dimarco JP, Ellenbogen KA, Estes NA, Freedman RA, Gettes LS, et al. ACC/AHA/HRS 2008 guidelines for Device-Based Therapy of Cardiac Rhythm Abnormalities: executive summary. Heart Rhythm. 2008;5(6):934-55. 
24. Jaarsma T, Strömberg A, De Geest S, Fridlund B, Heikkila J, Mårtensson $\mathrm{J}$, et al. Heart failure management programmes in Europe. Eur $\mathrm{J}$ Cardiovasc Nurs. 2006;5(3):197-205.

25. Strömberg A. Heart Failure Care: Studentlitteratur; 2005.

26. Strömberg A, Mårtensson J, Fridlund B, Levin L-Å, Karlsson J-E, Dahlström U. Nurse-led heart failure clinics improve survival and selfcare behaviour in patients with heart failure: results from a prospective, randomised trial. European heart journal. 2003;24(11):1014-23.

27. Gandhi S, Mosleh W, Sharma UC, Demers C, Farkouh ME, Schwalm J-D. Multidisciplinary heart failure clinics are associated with lower heart failure hospitalization and mortality: systematic review and metaanalysis. Canadian Journal of Cardiology. 2017;33(10):1237-44.

28. Riegel B, Jaarsma T, Strömberg A. A middle-range theory of self-care of chronic illness. Advances in Nursing Science. 2012;35(3):194-204.

29. Płotka A, Prokop E, Migaj J, Straburzyńska-Migaj E, Grajek S. Patients' knowledge of heart failure and their perception of the disease. Patient preference and adherence. 2017;11:1459.

30. Cannon JA, Moffitt P, Perez-Moreno AC, Walters MR, Broomfield NM, McMurray JJ, et al. Cognitive impairment and heart failure: systematic review and meta-analysis. Journal of cardiac failure. 2017;23(6):464-75.

31. Ampadu J, Morley JE. Heart failure and cognitive dysfunction. International journal of cardiology. 2015;178:12-23.

32. Whellan DJ, Goodlin SJ, Dickinson MG, Heidenreich PA, Jaenicke C, Stough WG, et al. End-of-life care in patients with heart failure. Journal of cardiac failure. 2014;20(2):121-34.

33. McKelvie RS, Moe GW, Ezekowitz JA, Heckman GA, Costigan J, Ducharme A, et al. The 2012 Canadian Cardiovascular Society heart failure management guidelines update: focus on acute and chronic heart failure. Canadian Journal of Cardiology. 2013;29(2):168-81.

34. Diop MS, Rudolph JL, Zimmerman KM, Richter MA, Skarf LM. Palliative care interventions for patients with heart failure: A systematic review and meta-analysis. Journal of palliative medicine. 2017;20(1):84-92.

35. Rogers JG, Patel CB, Mentz RJ, Granger BB, Steinhauser KE, Fiuzat M, et al. Palliative care in heart failure: the PAL-HF randomized, controlled clinical trial. Journal of the American College of Cardiology. 2017;70(3):331-41.

36. Brännström M, Hägglund L, Fürst CJ, Boman K. Unequal care for dying patients in Sweden: a comparative registry study of deaths from heart disease and cancer. European Journal of Cardiovascular Nursing. 2012;11(4):454-9. 
37. Gadoud A, Kane E, Macleod U, Ansell P, Oliver S, Johnson M. Palliative care among heart failure patients in primary care: a comparison to cancer patients using English family practice data. PloS one. 2014;9(11):e113188.

38. McMurray JJ, Adamopoulos S, Anker SD, Auricchio A, Böhm M, Dickstein K, et al. ESC guidelines for the diagnosis and treatment of acute and chronic heart failure 2012: The Task Force for the Diagnosis and Treatment of Acute and Chronic Heart Failure 2012 of the European Society of Cardiology. Developed in collaboration with the Heart Failure Association (HFA) of the ESC. Eur J Heart Fail. 2012;14(8):803-69.

39. Jaarsma TS, A., editor. How to approach palliative and end-of-life care? . New Delhi: Jaypee Brothers Medical Publishers 2016.

40. Buck HG, Zambroski CH. Upstreaming palliative care for patients with heart failure. J Cardiovasc Nurs. 2012;27(2):147-53.

41. Meyers DE, Goodlin SJ. End-of-life decisions and palliative care in advanced heart failure. Canadian Journal of Cardiology. 2016;32(9):1148-56.

42. Gelfman LP, Bakitas M, Warner Stevenson L, Kirkpatrick JN, Goldstein NE. The State of the Science on Integrating Palliative Care in Heart Failure. Journal of Palliative Medicine. 2017;20(6):592-603.

43. Kramer DB, Habtemariam D, Adjei-Poku Y, Samuel M, Engorn D, Reynolds MR, et al. The Decisions, Interventions, and Goals in ImplaNtable Cardioverter-DefIbrillator TherapY (DIGNITY) Pilot Study. Journal of the American Heart Association. 2017;6(9):eoo6881.

44. Kinch Westerdahl A, Sjöblom J, Mattiasson AC, Rosenqvist M, Frykman V. Implantable cardioverter-defibrillator therapy before death: high risk for painful shocks at end of life. Circulation. 2014;129(4):422-9.

45. Hill L, McIlfatrick S, Taylor B, Dixon L, Harbinson M, Fitzsimons D. Patients' perception of implantable cardioverter defibrillator deactivation at the end of life. Palliat Med. 2015;29(4):310-23.

46. Chow J, Senderovich H. It's Time to Talk: Challenges in Providing Integrated Palliative Care in Advanced Congestive Heart Failure. Current cardiology reviews. 2018.

47. Parker S, Clayton J, Hancock K, Walder S, Butow P, Carrick S, et al. A systematic Review of Prognostic/End-of-Life Communication with Adults in the Adcanced Stages of a Öife-Limiting Illness: Patient/Caregiver Preferences for the Content, Style, and Timong of Information. Journal of Pain and Symptom Management. 2007 July:81-93.

48. Klindtworth K, Oster P, Hager K, Krause O, Bleidorn J, Schneider N. Living with and dying from advanced heart failure: understanding the needs of older patients at the end of life. BMC geriatrics. 2015;15(1):1. 
49. Díez P, Alt-Epping B, Janssen DJ, Leget C, Albert M, Losada A, et al. issues in palliative care for patients with heart failure. European Journal of Palliative Care. 2017;24(1):18.

50. Selman L, Harding R, Beynon T, Hodson F, Coady E, Hazeldine C, et al. Improving end-of-life care for patients with chronic heart failure:"Let's hope it'll get better, when I know in my heart of hearts it won't”. Heart. 2007;93(8):963-7.

51. McIlfatrick S, Doherty LC, Murphy M, Dixon L, Donnelly P, McDonald K, et al. 'The importance of planning for the future': Burden and unmet needs of caregivers' in advanced heart failure: A mixed methods study. Palliative medicine. 2017:0269216317743958.

52. Romanò M, Piga M, Bertona R, Negro R, Ruggeri C, Zorzoli F, et al. Implantable cardioverter-defibrillator deactivation at the end of life: ethical, clinical and communication issues. Giornale italiano di cardiologia (2006). 2017;18(2):139-49.

53. Barclay S, Momen N, Case-Upton S, Kuhn I, Smith E. End-of-life care conversations with heart failure patients: a systematic literature review and narrative synthesis. Br J Gen Pract. 2011;61(582):e49-62.

54. Glaser BG, Strauss AL. Awareness of dying: Transaction Publishers; 1966.

55. McLeod-Sordjan R. Death preparedness: a concept analysis. Journal of advanced nursing. 2014;70(5):1008-19.

56. Remme WJ, McMurray JJ, Rauch B, Zannad F, Keukelaar K, Cohen-Solal A, et al. Public awareness of heart failure in Europe: first results from SHAPE. Eur Heart J. 2005;26(22):2413-21.

57. Hupcey JE, Kitko L, Alonso W. Patients' Perceptions of Illness Severity in Advanced Heart Failure. Journal of hospice and palliative nursing: JHPN: the official journal of the Hospice and Palliative Nurses Association. 2016;18(2):110-4.

58. Rogers AE, Addington-Hall JM, Aberg AJ, McCoy AS, Bulpitt C, Coats AJ, et al. Knowledge and communication difficulties for patients with chronic heart failure: qualitative study. BMJ. 2000 Septembre:605-7.

59. Schulz VM, Crombeen AM, Marshall D, Shadd J, LaDonna KA, Lingard L. Beyond Simple Planning: Existential Dimensions of Conversations With Patients at Risk of Dying From Heart Failure. Journal of pain and symptom management. 2017;54(5):637-44.

6o. Griffiths J, Ewing G, Wilson C, Connolly M, Grande G. Breaking bad news about transitions to dying: a qualitative exploration of the role of the district nurse. Palliative medicine. 2015;29(2):138-46.

61. Hanratty B, Lowson E, Holmes L, Grande G, Jacoby A, Payne S, et al. Breaking bad news sensitively: what is important to patients in their last year of life? BMJ supportive \& palliative care. 2012;2(1):24-8. 
62. Strachan PH, Ross H, Rocker GM, Dodek PM, Heyland DK. Mind the gap: Opportunities for improving end-of-life care for patients with advanced heart failure. Canadian Journal of Cardiology. 2009;25(11):635-40.

63. Friesinger GC, Butler J. End-of-life care for elderly patients with heart failure. Clinics in geriatric medicine. 2000;16(3):663-75.

64. Jackson VA, Jacobsen J, Greer JA, Pirl WF, Temel JS, Back AL. The cultivation of prognostic awareness through the provision of early palliative care in the ambulatory setting: a communication guide. Journal of palliative medicine. 2013;16(8):894-900.

65. The Swedish Government. Patient Act 2014: 821 (2014). Sweden: Social Department. Avilable from https://www.riksdagen.se/sv/dokumentlagar/dokument/svensk-forfattningssamling/patientlag-2014821_sfs2014-821. Last assesed 018-03-22.

66. Irving G, Holden J, Edwards J, Reeve J, Dowrick C, Lloyd-Williams M. Chronic heart failure guidelines: Do they adequately address patient need at the end-of-life? International journal of cardiology. 2013;168(3):23049.

67. Stiernstedt G, Zetterberg D, Ingmanson A. Effektiv vård. Stockholm: Statens Offentliga Utredningar, SOU; 2016.

68. Swedish Association of Local Authorities. Patientlagen ska stärka patientens ställning. Available from http://skl. se/halsasjukvard/patientinflytande/patientlagen. 2083. html; 2015. Assessed 2015-02-23.

69. M Johnson. R. Lehman KH, editor. Heart Failure and Palliative Care. Boca: CRC Press; 2016.

70. Brady DR. Planning for deactivation of implantable cardioverter defibrillators at the end of life in patients with heart failure. Critical care nurse. 2016;36(6):24-31.

71. Kirkpatrick JN, Fields AV, Ferrari VA. Medical ethics and the art of cardiovascular medicine. Lancet. 2010;376(9740):508-9.

72. Fried T, Bradley E, $\mathrm{O}^{\prime}$ Leary J. Prognosis communication in serious illness: perceptions of older patients, caregivers, and clinicians. J Am Geriatric Soc. 2003:1398-403.

73. Parker SM, Clayton JM, Hancock K, Walder S, Butow PN, Carrick S, et al. A systematic review of prognostic/end-of-life communication with adults in the advanced stages of a life-limiting illness: patient/caregiver preferences for the content, style, and timing of information. J Pain Symptom Manage. 2007;34(1):81-93.

74. Fellowes D, Wilkinson S, Moore P. Communication skills training for health care professionals working with cancer patients, their families and/or carers. Cochrane Database Syst Rev. 2004(2):CDo03751. 
75. Barnes S, Gott M, Payne S, Seamark D, Parker C, Gariballa S, et al. Communication in heart failure: perspectives from older people and primary care professionals. Health Soc Care Community. 2006;14(6):482-90.

76. Fund TK. EBCD: Experience-based co-design toolkit. 2011. Available from https://www.kingsfund.org.uk/projects/ebcd. Last accessed 3 November, 2017.

77. Borgstrom E, Barclay S. Experience-based design, co-design and experience-based co-design in palliative and end-of-life care. BMJ Supportive \& Palliative Care. 2017:bmjspcare-2016-001117.

78. Polit DF, Beck CT. Nursing Research: Generating and Assessing Evidence for Nursing Practice. 2012.

79. Koch T, Kralik D. Participatory action research in health care: John Wiley \& Sons; 2009.

80. Sanders E. \& Stappers P., Co-creation and the new landscapes of design, CoDesign, 4:1, (2008) 5-18, DOI: 10.1080/15710880701875068.

81. Jaarsma T, Strömberg A, Fridlund B, De Geest S, Mårtensson J, Moons P, et al. Sexual counselling of cardiac patients: nurses' perception of practice, responsibility and confidence. Eur J Cardiovasc Nurs. 2010;9(1):24-9.

82. K E, Simon A, A H. Verbal Reports as data. Psychological Review. 1980;87(3):215-51.

83. Krueger RA, Casey MA. Focus groups: A practical guide for applied research: Sage publications; 2014.

84. Morgan DL. Focus groups as qualitative research. 2. ed. Thousand Oaks, Calif.: Sage; 1997. viii, 80 s. p.

85. Rabiee F. Focus-group interview and data analysis. Proceedings of the nutrition society. 2004;63(4):655-60.

86. Polit DF \& Beck CT (2012): Nursing Research: Generating and Assessing Evidence for Nursing Practice.

87. Hjelm K, Bard K. Beliefs about health and illness in latin-american migrants with diabetes living in sweden. The open nursing journal. 2013;7:57.

88. Friedrichsen M. Crossing the border: Different ways cancer patients, family members and physicians experience information in the transition to the late palliative phase: Linköping University Electronic Press; 2002.

89. Garland EL, Bruce A, Stajduhar K. Exposing barriers to end-of-life communication in heart failure: an integrative review. Can J Cardiovasc Nurs. 2013;23(1):12-8. 
90. Spradley JP. Participant observation. 1980. New York: Wadsworth Thomson Learning.

91. Boyd H, McKernon S, Old A. Health service co-design: working with patients to improve healthcare services: guide and toolkit: Waitemata District Health Board; 2010.

92. Bowen DJ, Kreuter M, Spring B, Cofta-Woerpel L, Linnan L, Weiner D, et al. How we design feasibility studies. American journal of preventive medicine. 2009;36(5):452-7.

93. Hsieh HF, Shannon SE. Three approaches to qualitative content analysis. Qual Health Res. 2005;15(9):1277-88.

94. Graneheim UH, Lundman B. Qualitative content analysis in nursing research: concepts, procedures and measures to achieve trustworthiness. Nurse Educ Today. 2004;24(2):105-12.

95. Braun V, Clarke V. Successful qualitative research: A practical guide for beginners: Sage; 2013 .

96. Braun V, Clarke V. Using thematic analysis in psychology. Qualitative research in psychology. 2006;3(2):77-101.

97. Seeberger A. Den skamlösa nyfikenheten: Svante Weyler Bokförlag AB; 2010.

98. Momen NC, Barclay SI. Addressing 'the elephant on the table': barriers to end of life care conversations in heart failure - a literature review and narrative synthesis. Curr Opin Support Palliat Care. 2011;5(4):312-6.

99. Knowles MS, Holton III EF, Swanson RA. The adult learner: The definitive classic in adult education and human resource development: Routledge; 2014.

100. Anderson LW, Krathwohl DR, Airasian P, Cruikshank K, Mayer R, Pintrich $\mathrm{P}$, et al. A taxonomy for learning, teaching and assessing: A revision of Bloom's taxonomy. New York Longman Publishing Artz, AF, \& Armour-Thomas, E(1992) Development of a cognitive-metacognitive framework for protocol analysis of mathematical problem solving in small groups Cognition and Instruction. 2001;9(2):137-75.

101. Bacon J. The palliative approach: Improving care for Canadians with lifelimiting illnesses. Canadian Hospice Palliative Care Association. 2012;10.

102. Strachan PH, Joy C, Costigan J, Carter N. Development of a practice tool for community-based nurses: the Heart Failure Palliative Approach to Care (HeFPAC). European Journal of Cardiovascular Nursing. 2014;13(2):134-41.

103. Entwistle VA, Carter SM, Cribb A, McCaffery K. Supporting patient autonomy: the importance of clinician-patient relationships. J Gen Intern Med. 2010;25(7):741-5. 
104. Ekman I, Swedberg K, Taft C, Lindseth A, Norberg A, Brink E, et al. Person-centered care-Ready for prime time. European journal of cardiovascular nursing. 2011;10(4):248-51.

105. Epstein RM, Street JR RL. Patient-centered communication in cancer care: promoting healing and reducing suffering. 2007.

106. Voorhees J, Rietjens J, Onwuteaka-Philipsen B, Deliens L, Cartwright C, Faisst K, et al. Discussing prognosis with terminally ill cancer patients and relatives: a survey of physicians' intentions in seven countries. Patient education and counseling. 2009;77(3):430-6.

107. Cohen J, Bilsen J, Fischer S, Löfmark R, Norup M, van der Heide A, et al. End-of-life decision-making in Belgium, Denmark, Sweden and Switzerland: does place of death make a difference? Journal of Epidemiology \& Community Health. 2007;61(12):1062-8.

108. van der Wal MHL, Hjelmfors L, Martensson J, Friedrichsen M, Stromberg A, Jaarsma T. Variables Related to Communication About Prognosis Between Nurses and Patients at Heart Failure Clinics in Sweden and the Netherlands. J Cardiovasc Nurs. 2017.

109. Jones NR, Hobbs FR, Taylor CJ. The management of diagnosed heart failure in older people in primary care. Maturitas. 2017;106:26-30.

110. Agård A, Hermerén G, Herlitz J. When is a patient with heart failure adequately informed? A study of patients' knowledge of and attitudes toward medical information. Heart Lung. 2004;33(4):219-26.

111. Caldwell PH, Arthur HM, Demers C. Preferences of patients with heart failure for prognosis communication. Can J Cardiol. 2007;23(10):791-6.

112. Back A, Arnold R, Tulsky J. Mastering communication with seriously ill patients: balancing honesty with empathy and hope: Cambridge University Press; 2009.

113. Buetow S, Goodyear-Smith F, Coster G. Coping strategies in the selfmanagement of chronic heart failure. Family Practice. 2001;18(2):117-22.

114. Folkman S, Lazarus RS. The relationship between coping and emotion: Implications for theory and research. Social science \& medicine. 1988;26(3):309-17.

115. Allen LA, Stevenson LW, Grady KL, Goldstein NE, Matlock DD, Arnold $\mathrm{RM}$, et al. Decision making in advanced heart failure: a scientific statement from the American Heart Association. Circulation. 2012;125(15):1928-52.

116. Gillan PC, van der Riet PJ, Jeong S. End of life care education, past and present: a review of the literature. Nurse education today. 2014;34(3):331-42.

117. Jeffries PR. Simulation in nursing education: From conceptualization to evaluation: National League for Nursing; 2012. 
118. Gillan PC, Jeong S, van der Riet PJ. End of life care simulation: A review of the literature. Nurse education today. 2014;34(5):766-74.

119. Kaplonyi J, Bowles KA, Nestel D, Kiegaldie D, Maloney S, Haines T, et al. Understanding the impact of simulated patients on health care learners' communication skills: a systematic review. Medical education. 2017;51(12):1209-19.

120. Back AL, Arnold RM, Baile WF, Fryer-Edwards KA, Alexander SC, Barley GE, et al. Efficacy of communication skills training for giving bad news and discussing transitions to palliative care. Archives of internal medicine. 2007;167(5):453-60.

121. Sansoni JE, Grootemaat P, Duncan C. Question prompt lists in health consultations: a review. Patient education and counseling. 2015;98(12):1454-64.

122. Brandes K, Linn AJ, Butow PN, Weert J. The characteristics and effectiveness of Question Prompt List interventions in oncology: a systematic review of the literature. Psycho-Oncology. 2015;24(3):245-52.

123. van Weert JC, Jansen J, Spreeuwenberg PM, van Dulmen S, Bensing JM. Effects of communication skills training and a question prompt sheet to improve communication with older cancer patients: a randomized controlled trial. Critical reviews in oncology/hematology. 2011;80(1):14559.

124. Tanner CE, Fromme EK, Goodlin SJ. Ethics in the treatment of advanced heart failure: palliative care and end-of-life issues. Congestive Heart Failure. 2011;17(5):235-40.

125. Clayton JM, Butow PN, Tattersall MH, Devine RJ, Simpson JM, Aggarwal G, et al. Randomized controlled trial of a prompt list to help advanced cancer patients and their caregivers to ask questions about prognosis and end-of-life care. Journal of Clinical Oncology. 2007;25(6):715-23.

126. Walczak A, Butow PN, Tattersall MH, Davidson PM, Young J, Epstein $\mathrm{RM}$, et al. Encouraging early discussion of life expectancy and end-of-life care: A randomised controlled trial of a nurse-led communication support program for patients and caregivers. International journal of nursing studies. 2017;67:31-40.

127. Walczak A, Henselmans I, Tattersall MH, Clayton JM, Davidson PM, Young $\mathrm{J}$, et al. A qualitative analysis of responses to a question prompt list and prognosis and end-of-life care discussion prompts delivered in a communication support program. Psycho-Oncology. 2015;24(3):287-93.

128. Martinali J, Bolman C, Brug J, van den Borne B, Bar F. A checklist to improve patient education in a cardiology outpatient setting. Patient education and Counseling. 2001;42(3):231-8. 
129. Bolman C, Brug J, Bär F, Martinali J, van den Borne B. Long-term efficacy of a checklist to improve patient education in cardiology. Patient education and counseling. 2005;56(2):240-8.

130. McLawhorn VC, Vess J, Dumas BP. Integrating a Question Prompt List on an Inpatient Oncology Unit to Increase Prognostic Awareness. Clinical journal of oncology nursing. 2016;20(4):385-90.

131. Steel A, Bakhai A. Proposal for routine use of mortality risk prediction tools to promote early end of life planning in heart failure patients and facilitate integrated care. Int J Cardiol. 2013;167(1):280-2.

132. Feldman-Stewart D, Brundage MD, Tishelman C, Team SC. A conceptual framework for patient-professional communication: an application to the cancer context. Psychooncology. 2005;14(10):801-9; discussion 10-1.

133. Slater L. Person-centredness: a concept analysis. Contemporary Nurse. 2006;23(1):135-44.

134. Steinberg L, White M, Arvanitis J, Husain A, Mak S. Approach to advanced heart failure at the end of life. Canadian Family Physician. 2017;63(9):674-80.

135. Lincoln YS, Guba EG. Naturalistic inquiry: Sage; 1985.

136. Ferguson L. External validity, generalizability, and knowledge utilization. Journal of Nursing Scholarship. 2004;36(1):16-22.

137. Steinke EE, Patterson-Midgley P. Sexual counseling of MI patients: nurses' comfort, responsibility, and practice. Dimens Crit Care Nurs. 1996;15(4):216-23.

138. Lambert SD, Loiselle CG. Combining individual interviews and focus groups to enhance data richness. Journal of advanced nursing. 2008;62(2):228-37.

139. Walczak A, Butow PN, Davidson PM, Bellemore FA, Tattersall MH, Clayton JM, et al. Patient perspectives regarding communication about prognosis and end-of-life issues: how can it be optimised? Patient Education and Counseling. 2013;90(3):307-14.

140. Kaplowitz MD, Hoehn JP. Do focus groups and individual interviews reveal the same information for natural resource valuation? Ecological Economics. 2001;36(2):237-47.

141. Leung W-C. Why is evidence from ethnographic and discourse research needed in medical education: the case of problem-based learning. Medical Teacher. 2002;24(2):169-72.

142. Coffey A. The ethnographic self: Fieldwork and the representation of identity: Sage; 1999.

143. Savage J. Ethnography and health care. BMJ: British Medical Journal. 2000;321(7273):1400. 
144. Willig C. Introducing qualitative research in psychology: McGraw-Hill Education (UK); 2013.

145. Marton F. Phenomenography-describing conceptions of the world around us. Instructional science. 1981;10(2):177-200.

146. Graneheim UH, Lindgren B-M, Lundman B. Methodological challenges in qualitative content analysis: A discussion paper. Nurse education today. 2017;56:29-34.

147. Sims-Schouten W, Riley SC, Willig C. Critical realism in discourse analysis: A presentation of a systematic method of analysis using women's talk of motherhood, childcare and female employment as an example. Theory \& Psychology. 2007;17(1):101-24.

148. Gillan PC, Parmenter G, van der Riet PJ, Jeong S. The experience of end of life care simulation at a rural Australian University. Nurse education today. 2013;33(11):1435-9. 


\section{Heart failure}

\section{Conversations about the illness trajectory}

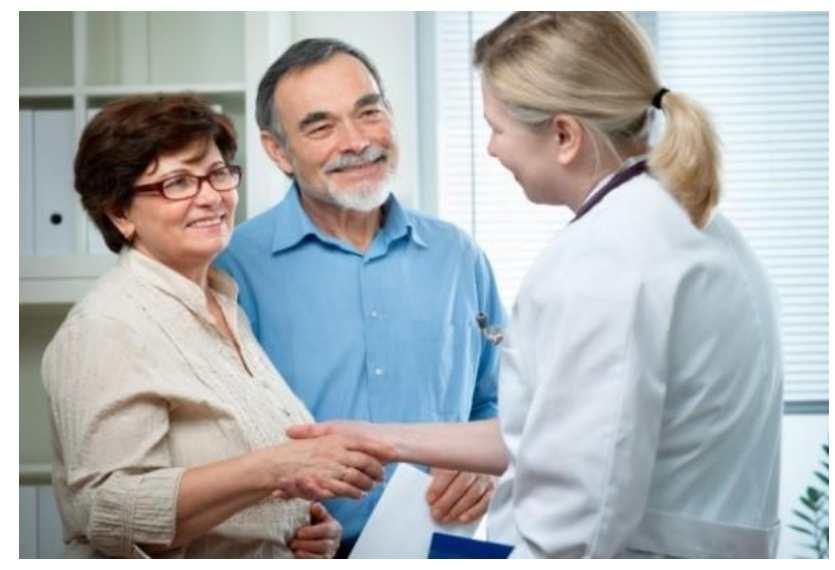

A guide ahead of your appointment at the public health care centre or the hospital

\section{I..0}




\section{Appendix 1}

\section{Introduction}

Many heart failure patients and their family members have questions about the Heart Failure (HF) trajectory and the future. However, it can be hard to initiate a conversation about these topics with health care professionals. In this booklet you will find examples of other patients' and family member's questions about the future and what it is like to live with heart failure. It can be used as a guide ahead of a conversation with health care professionals and you can choose the questions that apply to your situation.

You probably also want to ask questions about self-care, medication, physical activity, etc. However, this booklet only focuses on questions about the future and the trajectory of heart failure.

In the booklet you can tick the boxes for the questions you would like to discuss. You can also make a note of questions you would like to discuss that are not included in the list. 


\section{Appendix 1}

\section{Heart failure and its impact on daily life}

Tick the boxes for the questions you want to discuss

$\square \quad$ What does heart failure entail?

$\square \quad$ Is heart failure a serious illness?

$\square \quad$ Is heart failure a lifelong illness?

$\square \quad$ What can I do to improve my prognosis?

$\square \quad$ What can I do to improve my condition?

$\square \quad$ What is the likely impact of heart failure on my future?

$\square \quad$ What goals are realistic for the future?

$\square \quad$ What symptoms might I experience when my condition deteriorates in the future, and what should I do if they manifest themselves?

Other questions I want to ask: 
Appendix 1

\section{Help and support when the illness deteriorates}

Tick the boxes for the questions you want to discuss

$\square \quad$ Who can I talk to about things that worry or bother me?

$\square \quad$ Who can my family talk to about things that worry or bother them?

$\square \quad$ What treatment is available to me when my illness deteriorates?

$\square \quad$ What support is available to me if I deteriorate and cannot look after myself?

$\square \quad$ Can I choose where I want to be cared for when I deteriorate?

$\square \quad$ Is it possible to be cared for at home when I deteriorate?

$\square \quad$ What support is available to me if I choose to be cared for at home?

$\square \quad$ Who can help me decide about my care?

$\square \quad$ Who will have the overall responsibility for my care if I deteriorate?

\section{Other questions I want to ask:}




\section{The end-of-life}

The questions below might not apply to your current situation. You do not need to read them if you do not want to, but you might want to discuss them in the future.

Tick the boxes for the questions you want to discuss

$\square \quad$ Will someone tell me when I am approaching the end-of-life?

$\square \quad$ Is it possible to predict how long someone has left to live?

$\square \quad$ Will the end-of-life be prolonged when I have heart failure?

$\square \quad$ How will I feel during my last days of life?

$\square \quad$ What will happen to my heart failure treatment at the end-of-life?

$\square \quad$ What happens in the body when you die from heart failure?

$\square \quad$ Are breathing problems common at the end-of-life?

$\square \quad$ Is pain common at the end-of-life?

$\square \quad$ Is it common to experience anxiety at the end-of-life?

\section{Other questions I want to ask:}




\section{Appendix 1}

\section{Other questions that family members may want to discuss}

Tick the boxes for the questions you want to discuss

$\square \quad$ How do we agree on what the person who is ill can/should/is allowed to do?

$\square \quad$ If needed, how do I get help to look after the person who is ill?

$\square \quad$ How do I best help the person who is ill if they deteriorate?

$\square \quad$ Who can I turn to if I have concerns about the care given to the person who is ill?

$\square \quad$ Who can I talk to about things that worry and bother me?

The questions below might not apply to your current situation. You do not need to read them if you do not want to, but you might want to discuss them in the future.

$\square \quad$ What support is there for me when the illness deteriorates and I feel that I cannot do anymore?

$\square \quad$ How do I know that the end of life is approaching?

$\square \quad$ What do I reply to the question "Am I going to die now?"?

$\square \quad$ How do patients react when their disease deteriorates?

$\square \quad$ How do family members react when the illness deteriorates?

$\square \quad$ How do I know if the patient has passed away?

$\square \quad$ What happens with the dead body?

$\square \quad$ Who can help me organise the funeral?

\section{Other questions I want to ask:}


Appendix 1

Other questions for patients with a heart failure pacemaker or an implantable cardioverter defibrillator

Tick the boxes for the questions you want to discuss

$\square \quad$ What will happen to my implantable cardioverter defibrillator (ICD) at the endof-life?

$\square \quad$ What impact will my heart failure pacemaker (CRT), pacemaker or implantable cardioverter defibrillator (ICD) have on my last days of life?

$\square$ What will happen to my ICD/CRT/pacemaker treatment at the end-of-life?

$\square \quad$ How will my ICD be switched off?

$\square \quad$ What will happen to my heart if my ICD is switched off?

$\square \quad$ Can my ICD be switched off without mine or my familie's knowledge?

Other questions I want to ask: 
Appendix 1

Other comments: 


\section{Curriculum of the communication course}

\section{To discuss the HF trajectory}

This practical communication course aims to stimulate communication about the HF trajectory and end-of-life care between patient/family and health care professionals using an approach that is individualized to the situation and meets the needs of the patient and the family.

The course is designed for health care professionals working in the area of cardiology.

During the course the participant will gain knowledge about the importance of discussing the HF trajectory and end-of-life care with the patient and the family. The participant will have the chance to practice discussing the trajectory and end-of-life care with simulated patients and family members.

A practical booklet (a Question Prompt List) will be provided, and participants can hand it out to patients and family members in their clinical practice. The booklet is a structured list of questions that serves as a prompt for patients to think of questions about the trajectory and end-of-life care to ask the professional. By enabling patients to ask questions concerning their future, communication may be improved.

\section{Learning goals:}

- Understand the importance of discussing the HF trajectory and end-of-life care with patient and family, using an individualized approach

- Understand how barriers and facilitators can impact patients' and family members' reactions and preferences for communication about the HF trajectory and end-of-life care

- Reflect on own possible emotional difficulties in communication situations and plan for how to deal with such issues

- Gain knowledge on how to discuss the HF trajectory and end-of-life care with patients and family using an individualized approach

- Develop and demonstrate skills for selecting and using appropriate communication strategies in each specific communication situation, based on the individual needs of the patient and the family members

- Demonstrate skills, knowledge and confidence about discussing the questions listed in the QPL with patients and family, focusing on their needs and specific situation. 


\section{Reflection task 1 (online)}

Aim: To make the participant reflect upon what timepoints can be considered suitable to discuss the HF prognosis. What timepoints are considered not suitable and why?

Task: Based on your profession, think about the timepoint that you find suitable for talking about prognosis with a HF patient for the first time. Explain why you feel that the chosen timepoint is suitable.

\section{Reflection task 2 (online)}

Aim: To make the participant reflect upon the questions in the QPL and what their role should be in such conversations. The participant is also given the opportunity to reflect upon the knowledge and skills required for individualized discussions about the questions with patients and family members.

Task: Prepare for a group discussion ahead of the training day at the university

1) Read the booklet "Heart failure - Conversations about the illness trajectory " and think about what questions you have knowledge about and are able to discuss with the patient and their family members.

2) Based on your profession, reflect upon what your role should be in the communication about prognosis and end-of-life.

3) Select three questions that you feel would be difficult to discuss with a patient and their family members.

Your individual tasks will form the basis for the group discussions during the training day. 


\section{Group discussion (at the university)}

Aim: Continuation of reflections regarding the things that are experienced as easy or difficult in the communication about the HF trajectory. Through group discussions, the participants can listen to other people's experiences and learn from their communication strategies.

Task: Four groups with five participants per group. The groups are placed in separate rooms. Based on reflection task 1 , they should discuss:

1) Which questions in the booklet do you think are easy to discuss?

2) Which questions do you need more knowledge about in order to be able to discuss them in a good way?

One researcher participates in each group, helping to create a good climate for discussion and asking challenging follow-up questions to encourage the participants to make reflections.

\section{Simulation (at the university)}

Aim: The participants are given an opportunity to practice and discuss the questions in the booklet. Thereby, the participants' ability to discuss the HF trajectory is developed. As this takes place in a safe and simulated environment, the participants can make mistakes without causing any harm.

Task: To practice communication with a simulated patient/family members about the questions in the booklet "Heart failure - conversations about the illness trajectory". To observe and reflect upon other participants' simulated conversations.

Set-up: Two groups with ten participants in each group. Two researchers participate as group leaders in each group together with the simulated patient/family members.

The participants choose if they want to practice or act as observers. The participants choose what questions they want to practice discussing, and the group leaders encourage the participants to challenge themselves to discuss the more difficult questions.

The conversations will be commented on by the group leaders, the simulated patient and the other course participants, to provide feed-back on room for improvement.

The course participants can take pauses if the simulated conversations get too stressful and then go on with the practice. 


\section{Reflection task 3 (online)}

Aim: To make the participants use the QPL in clinical practice and allow them to practice conversations about the HF trajectory. It is important that the participants are able to reflect upon their own role in the conversation and how they can influence the conversation through open-ended questions and an empathic attitude towards the patient and their family members.

Patients with heart failure and their family members rarely discuss the HF trajectory with health care professionals. Therefore, they are often unprepared for the unpredictable trajectory of heart failure. Health care professionals, on the other hand, are unsure about how to communicate with patients and family members about the HF trajectory without making them worried. The booklet with questions for discussion is to be used as a communication aid that can help patients, family members and health care professionals talk about these topics. The booklet contains questions regarding how heart failure can affect daily life, as well as help and support during deterioration and end-of-life.

Task: Give the booklet "Heart failure - conversations about the illness trajectory" to one patients and/or one family members. Give the patient and/or their family member time to read it and highlight questions that they want to discuss. Discuss the selected questions. When the conversation has ended, write down what worked and what did not work during the conversation. Reflect upon your role in the conversation, your strengths and what you can improve upon.

You are free to choose the timepoint you find the most suitable to give the booklet to the patient/family members. 


\section{Papers}

The papers associated with this thesis have been removed for copyright reasons. For more details about these see:

http://urn.kb.se/resolve?urn=urn:nbn:se:liu:diva-145585 